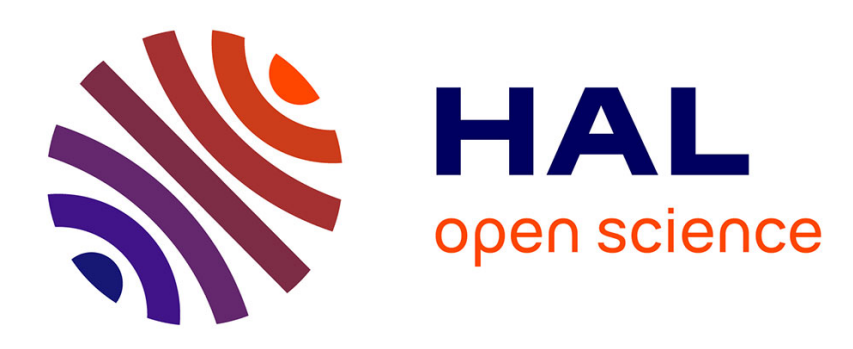

\title{
Recent advances in dioxaborine-based fluorescent materials for bioimaging applications \\ Mayeul Collot
}

\section{To cite this version:}

Mayeul Collot. Recent advances in dioxaborine-based fluorescent materials for bioimaging applications. Materials Horizons, 2020, 8, pp.501 - 514. 10.1039/d0mh01186j . hal-03419750

\author{
HAL Id: hal-03419750 \\ https://hal.science/hal-03419750
}

Submitted on 10 Nov 2021

HAL is a multi-disciplinary open access archive for the deposit and dissemination of scientific research documents, whether they are published or not. The documents may come from teaching and research institutions in France or abroad, or from public or private research centers.
L'archive ouverte pluridisciplinaire HAL, est destinée au dépôt et à la diffusion de documents scientifiques de niveau recherche, publiés ou non, émanant des établissements d'enseignement et de recherche français ou étrangers, des laboratoires publics ou privés. 


\section{ARTICLE}

\section{Recent Advances on Dioxaborine-Based Fluorescent Materials for Bioimaging Applications}

Received 00th January 20xx Accepted 00th January 20xx DOI: $10.1039 / x 0 x x 00000 x$

\section{Introduction}

Fluorescent materials have continuously demonstrated their efficacies and usefulness in bioimaging, ${ }^{1,2}$ thus asserting their huge impact in the fields of biology and medicine. ${ }^{3,4,5}$ The fast development of new microscopy techniques as well as the growing demand of high performance fluorescent materials require new and adapted improvements of their photophysical properties. New chemical designs were shown to be efficient for tuning and improving various properties including absorption and emission wavelength, photostability and brightness. ${ }^{6,7}$ The brightness is a particularly important feature in bioimaging as high brightness insure high signal/ background ratio and thus better quality of imaging. The brightness is defined as the product of the molar extinction coefficient (expressed in $\mathrm{M}^{-1} \cdot \mathrm{cm}^{-1}$ ) and the quantum yield (ratio between the emitted photons and the absorbed photons). These two photophysical characteristics can be enhanced at the molecular level by limiting the rotations around bonds. ${ }^{8}$ Indeed, at the excited state, rotations promote vibrational relaxations that compete with radiative transitions thus lowering the quantum yield. Moreover, rotations increase vibrational levels and leads to broad absorption spectra that lower the extinction coefficient at the maximum absorption wavelength. Fixing rotations can be achieved by involving bonds in a cycle. ${ }^{9}$ To this endeavor, complexation of heteroatoms such as nitrogen or oxygen by a boron complex proved to be efficient. In the field of fluorescent materials, the most famous example is represented by conjugated

\footnotetext{
a. Laboratoire de Bioimagerie et Pathologies, UMR 7021, CNRS/Université de Strasbourg, 74 route du Rhin, 67401 Illkirch-Graffenstaden, France.

* Corresponding author, E-mail: mayeul.collot@unistra.fr
}

dipyromethenes that are virtually non-fluorescent due to possible rotations whereas their rigid boron complex, known as BODIPY, are highly fluorescent (Figure $1 \mathrm{~A}) .{ }^{10}$

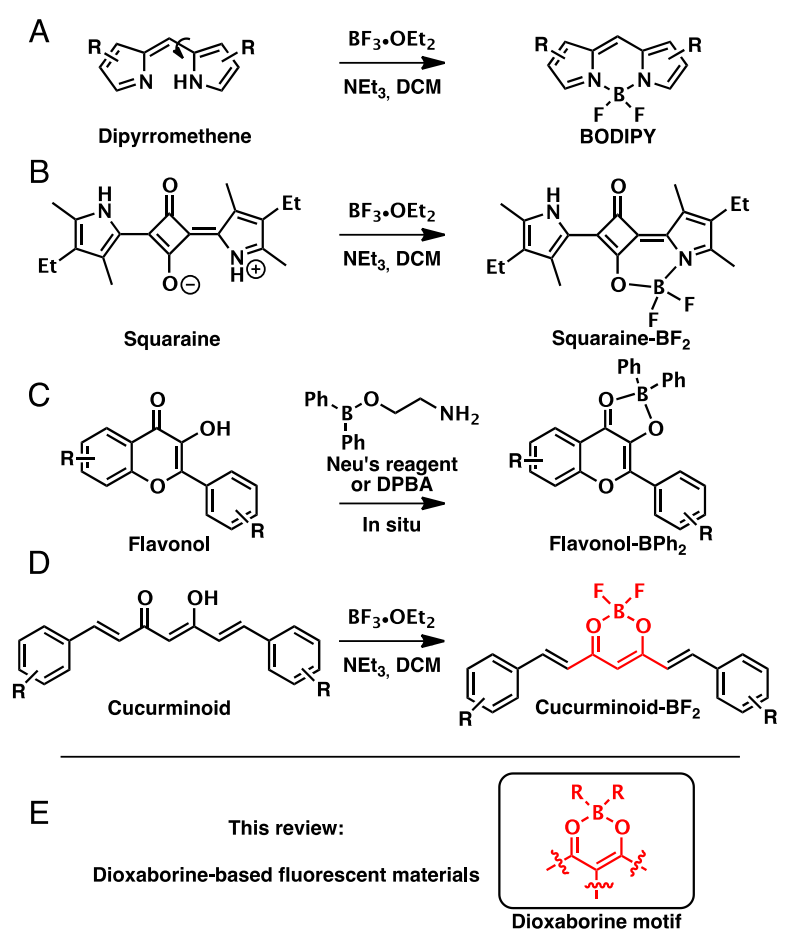

Figure 1. Examples where a boron complex is formed to enhance the fluorescent properties (A-D) and the dioxaborine motif (E). (A) Formation of fluorescent BODIPY by boron complexation of non-fluorescent dipyrromethene. (B) Fluorescent enhancement of squaraine dye by boron complexation. (C) Use of Neu's reagent to fluorescently reveal the flavanols. (D) Complexation of boron by curcuminoids leading to DBFM. (E) The dioxaborine motif. $R$ are substituents that can be connected to the structure. 
Additionally, it was recently shown that the quantum yield of emissive fluorophores such as squaraine $(\phi=0.49)$ can almost be doubled by boron complexation to reach $\phi=0.92$ (Figure 1B). ${ }^{11}$ This approach is also widely used especially in plant science to probe flavanols that are a class of flavonoids. Indeed, when flavanols react in situ with diphenylboric acid 2aminoethyl ester (DPBA) also called Neu's reagent, the fluorescence of the obtained diphenyl dioxaborine flavanols (flavanol-BPh ${ }_{2}$ ) is highly enhanced and become detectable by microscopy (Figure 1C). ${ }^{12}$ Natural curcuminoids and their synthetic analogues possess a diketone moiety that readily reacts with $\mathrm{BF}_{3} \cdot \mathrm{OEt}_{2}$ to form dioxaborine derivatives with enhanced fluorescent properties compared to their noncomplexed parents (Figure 1D). ${ }^{13}$ This approach rapidly led to new materials, ${ }^{14}$ and numerous fluorescent probes (vide infra). In parallel to these complexes, other fluorescent materials possessing a dioxaborine motif were developed and studied

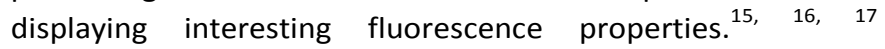
Consequently, dioxaborine-based fluorescent materials (DBFM) containing a difluoroboron $\beta$-diketonate moiety (Figure 1E) are drawing a particular attention in the field of bioimaging due to their accessible synthesis and their appealing features compared to their non-complexed parents, including bathochromic shift, hyperchromism and enhanced brightness. $^{18,} 19$ Moreover, DBFM were shown to have important two-photon absorption properties which make them suitable for two-photon excitation microscopy (TPE). ${ }^{13}$ As examples, we recently reported a new class of DBFM called StatoMerocyanines (see section 5.2), with exceptionally high two-photon absorption reaching cross sections as high as $13,300 \mathrm{GM}$ (at $770 \mathrm{~nm}$ in DMSO). ${ }^{20}$ One year later Ashoka et al. reported DXB-NIR (see section 5.1) with 13,800 GM (at $930 \mathrm{~nm}$ in dichloromethane). ${ }^{21}$ In addition to these properties DBFM can be laser dyes, ${ }^{22} 232425$ and were also shown to display bright solid state emission, ${ }^{26,27,28}$ mechanofluorochromism, ${ }^{29}$, 30, 31, 32 phosphorescent properties, ${ }^{33,34,35}$ thermally activated delayed fluorescence, ${ }^{36}$ thermally responsive properties, ${ }^{37}$ as well as aggregation induced emission (AIE) properties. ${ }^{38,39,19,40}$ Maeda and coworkers also demonstrated the unique applications of DBFM in anion complexation. ${ }^{41,42,43,44,45,46}$ In this review we focused on the recent advances (over the last 10 years) on dioxaborine-based fluorescent materials (DBFM), covering molecular probes and nanomaterials that found their application in bioimaging.

\section{Probes for biomolecules}

In this section we report DBFM that were design to act as probes for various biomolecules including nucleic acids (DNA), proteins (circulating proteins, receptors, aggregates) as well as enzymatic activity.
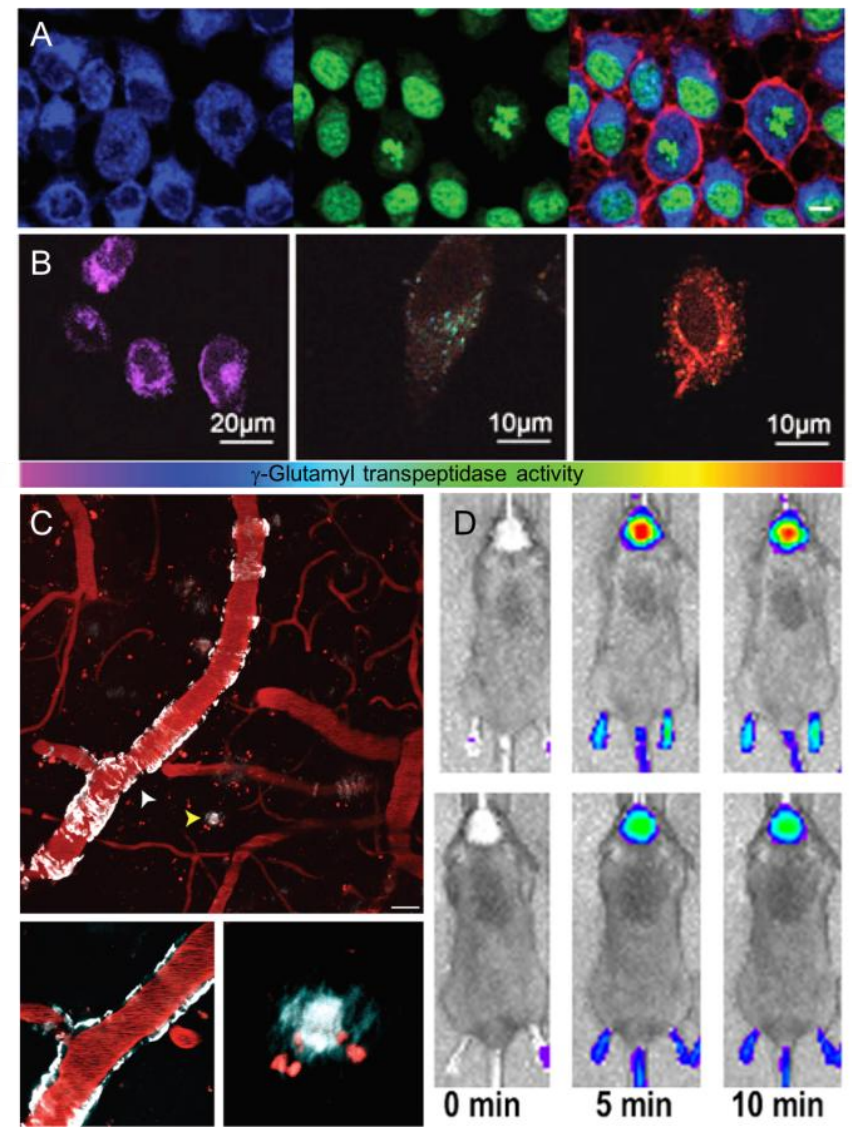

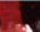
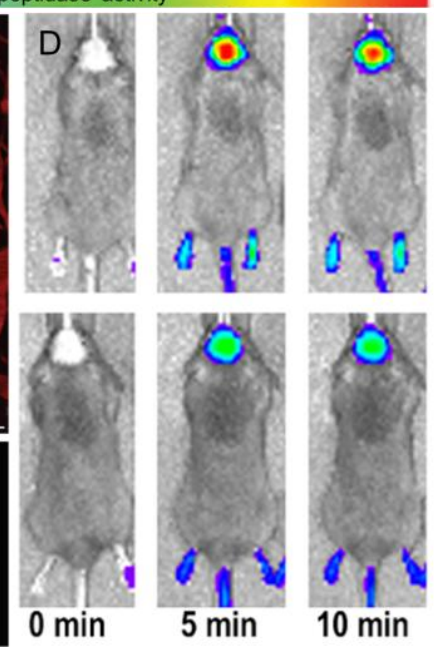

Figure 2. Representative examples of bioimaging performed with DBFM probes for biomolecules. (A) MCF7 cells stained with $\mathbf{2}$ showing a dual labelling of the cytoplasm (blue) and the nucleus (green). Ref. 48, adapted by permission of The Royal Society of Chemistry. (B) Ratiometric imaging using Glu-DFB-biotin depicting the $\gamma$-glutamyl transpeptidase activity in QSG7701 (left), HeLa (middle) and HepG2 (right). Ref. 51, adapted by permission of The Royal Society of Chemistry. (C) Two-photon in vivo images of mouse brain using CRANAD-28 (white signal) revealed cerebral amyloid angiopathies (white arrowhead, left panel) and $A \beta$ plaques (yellow arrowhead). Ref. 57, adapted by permission of The Royal Society of Chemistry. (D) NIR fluorescence in vivo imaging using CRANAD-58 probing soluble A $\beta$ species in APP-PS1 AD mouse model (upper panel) and control mouse (lower panel), left images are before injection. Adapted with permission from ref 56. Copyright (2013) American Chemical Society.

\subsection{Probes for DNA}

In 2013 Wilson et al. developed a DNA-targeting fluorogenic probe called Miami Yellow (MY) based on diphenyl dioxaborine (Figure 3) that gradually increases its fluorescence intensity-depending on the length of the AT (adenine, thymine) pair tracts. ${ }^{47}$ Binding of $\mathrm{MY}$ to AT-rich regions was also accompanied by a bathochromic shift and allowed selective imaging of HEK293 cells' nuclei using a laser line at $514 \mathrm{~nm}$. Based on the same $\mathrm{N}$-Methyl piperazine-ended moieties, the same group introduced two red shifted extended DNA-targeting analogues based on hemicurcuminoid (2) and curcuminoid (4) $-\mathrm{BF}_{2}$ complexes (Figure 3). Taking advantage of its environmental sensitivity, $\mathbf{2}$ was readily resolved into separated microscopy channels, thus allowing dual-color cell imaging of the cytoplasm and the nucleus (Figure 2A). ${ }^{48}$ 

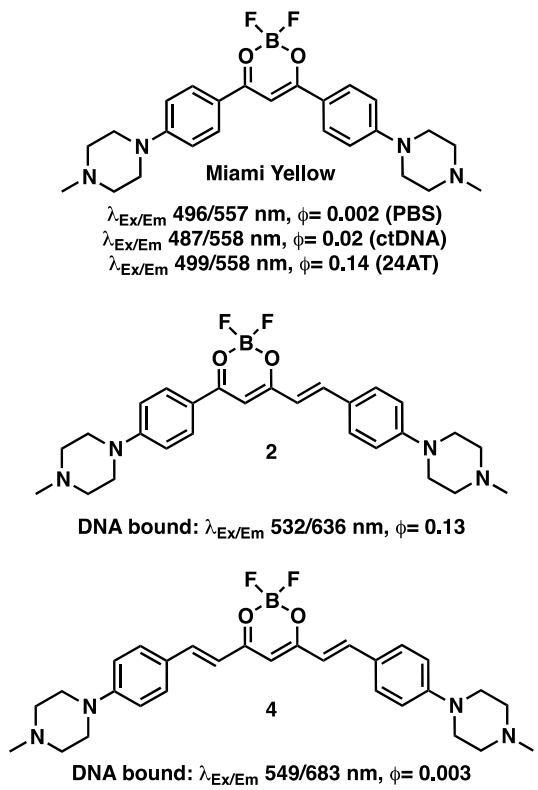

Figure 3. DBFM as DNA probes.

\subsection{Probes for proteins / enzymatic activity}

Serum albumin (SA) is the most abundant transport protein in the serum. In 2017, Sun et al. developed an extended coumarin CBF, a fluorogenic probe that binds SA in an equimolar manner and with a high selectivity compared to other proteins. $^{49}$ Although CBF displayed positive solvatochromic properties that could explain the fluorescence enhancement as well as the blue shift observed upon binding to SA, the authors were able to show that CBF actually underwent an hydrolysis leading to its non-complexed form, RC (Figure 4A). Fluorescence imaging performed after incubating cancer cells (HeLa) and L929 cells in the presence of CBF-labelled SA suggested that tumor cells absorbed more SA than the non-cancer line. Noteworthy that in this example the dioxaborine is the non-fluorescent form whereas the noncomplexed RC is the emitting moiety, thus constituting an original approach in this review. Bovine Serum Albumin (BSA) was also labeled in a non-specific manner, using 3 (Figure 4B), an amine reactive fluorogenic probe developed by Gerasov et $a l^{50} 3$ is a non-fluorescent water soluble bicyclic dioxaborine which was shown to spontaneously react with amines of proteins to give $3^{\prime}$, its corresponding fluorescent open form thus allowing covalent fluorescent labeling of protein for gel electrophoresis detection.

In 2018, bai et al. described Glu-DFB-biotin (Figure 4C), a ratiometric probe for $\gamma$-glutamyl transpeptidase (GGT) activity. $^{51}$ Glu-DFB-biotin is a red-emitting dioxaborine curcuminoid which bears at one end a biotin moiety that target cancer cells that overexpress biotin receptors, ${ }^{52}$ and at the other end a glutamate moiety. Upon $\gamma$-glutamyl transpeptidase activity the glutamate is hydrolyzed and leads to $\mathbf{N H}_{2}$-DFB-biotin that emits in the near infrared. This dual color probe enabled the tracking of endogenous GGT activity using ratiometric imaging in live hepatocyte cells QSG-7701 as control and cancer cell lines HepG2 and HeLa (Figure 2B). The use of a GGT inhibitor further proved the selectivity of this this dual-channel probe.

A
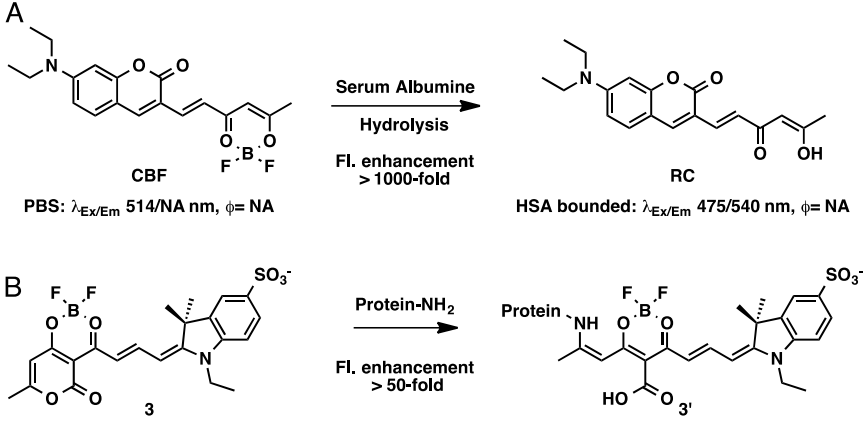

$\lambda_{E \times / E m} 560 / 602 \mathrm{~nm}, \phi=N A$

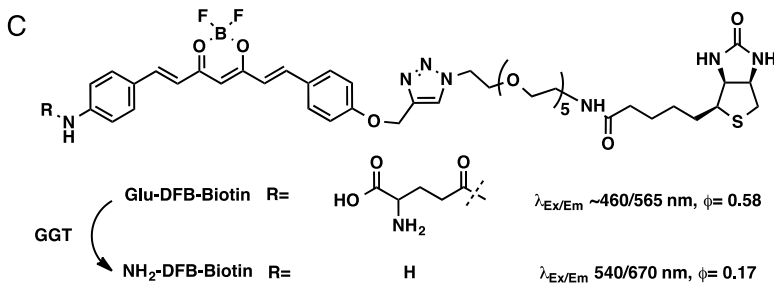

Figure 4. DBFM used as protein probe (A, B) and ratiometric enzymatic activity reporter (C).

\subsection{Probes for amyloid beta $(A \beta)$ species}

Amyloid beta $(A \beta)$ species are proteins existing as soluble monomers, dimers and oligomers or insoluble aggregates, fibrils and plaques. $A \beta$ were shown to be involved in the neuropathology associated to Alzheimer's disease (AD) making their fluorescent detection highly desirable in bioimaging. To this aim, Moore and Ran associated their efforts to develop several $A \beta$ fluorogenic probes. In 2009, they introduced the CRANAD family. ${ }^{53}$ Based on pioneer works showing that curcumin, a natural pigment, interacted with $A \beta$ aggregates with high picomolar affinity ${ }^{54}$ and could be used as a marker, ${ }^{55}$ they intend to develop a curcumin-based NIR fluorescent probe for $A \beta$ aggregates. In a first attempt, CRANAD-1, the corresponding difluoroboron complex of curcumin was obtained (Figure 5A). Although CRANAD-1 displayed a significant red shifted emission compared to the parent curcumin (Figure 5A), it did not emit in the NIR region. In a second attempt, the oxygen-based substituents of CRANAD-1 were replaced by more electron-donating moieties (dimethylamino) and led to CRANAD-2, a NIR fluorogenic probe (Figure 5A). CRANAD-2 binds selectively to $A \beta$ aggregates with a high affinity $(\mathrm{Kd}=38 \mathrm{nM})$, accompanied by a $90 \mathrm{~nm}$ blue shift (from 805 to $715 \mathrm{~nm}$ ) and a 70-fold fluorescence enhancement. It was successfully used to detect $A \beta$ plaques in both in vitro and in vivo experiments.

In 2013, Moore and Ran pushed further their investigation. Assuming that CRANAD interacted with the sequence HHQKLVFF present in the $A \beta$ species, they developed an asymmetric CRANAD-2 analogue, CRANAD-58 (Figure 5A), in which an aniline moiety was kept to interact with the hydrophobic segment (LVFF), and a more hydrophilic pyridyl 
moiety was introduced to interact with the hydrophilic segment (HHQK). ${ }^{56}$ Thanks to this rational design CRANAD-58 was successfully used to image both insoluble and soluble $A \beta$ species in vitro and in vivo (Figure 2D).

The next year, arisen from a rational design, the same lead authors intended to develop a brighter CRANAD probe. ${ }^{57}$ Indeed, assuming that tautomerization led to low quantum yields, the aniline moieties of CRANAD-2 were replaced by $\mathrm{N}$ phenyl pyrazoles. This approach proved to be successful and led to CRANAD-28 (Figure 5A) that displayed significant higher quantum yields (up to 1.0 in ethanol) compared to similar CRANAD probes. Noteworthy, CRANAD-28 only emits in the visible range and could not be classified as fluorogenic probe as its fluorescence intensity was decreased upon binding to $A \beta$ species. Nevertheless, due to its ability to cross the blood brain barrier, its high affinity towards $A \beta$ species and its high brightness, CRANAD-28 was successfully used in two-photon in vivo imaging to label both $A \beta$ plaques and cerebral amyloid angiopathies (Figure 2C). CRANAD-28 was recently used for further investigation on its probing abilities. ${ }^{58}$

In 2015, the same group developed a novel symmetrical member of the CRANAD family, namely CRANAD-3 (Figure 5A) to monitor changes of $A \beta s$ during therapy. ${ }^{59}$ In order to increase the interactions with monomeric or oligomeric A $340 / 42$, the authors replaced the aniline of CRANAD-58 by a pyridyl moiety to obtain CRANAD-3. As expected, the latter exhibited strong nanomolar-binding constant with $A \beta 40 / 42$ monomers, accompanied with a 12.3 and 39.5-fold fluorescence enhancement respectively. The NIR CRANAD-3 was then used to monitor the effects of drug treatments on the changes of $A \beta$ s in an $A D$ mouse model.

In 2017, Ran et al. reached an important achievement as they obtain a NIR probe selective for soluble forms of $A \beta$ species. ${ }^{60}$ The stereo-hindrance of CRANAD-3 was tuned by addition of phenoxy-alkyl chains at the central carbon of the dioxaborine. This approach led to a hit, CRANAD-102 (Figure 5A) that displayed significant selectivity for soluble $A \beta$ over insoluble ones with high affinity ( $7.5 \mathrm{nM}, 275 \mathrm{nM}$ respectively). Due to excellent blood brain barrier penetration, in vivo NIR imaging was successfully performed.

In 2019, the same group explored the potential of hemicurcuminoids as $A \beta$ species probes for both fluorescent and positron emission tomography (PET) imaging. ${ }^{61}$ Keeping the dioxaborine scaffold, they developed F-CRANAD 101 (Figure 5A), a hemicurcuminoid displaying a pyrazole with balanced hydrophobicity and a cyclobutyl moiety at one end to lower the reactivity of the diketone moiety. At the other end a tosylate allowed a $\mathrm{S}_{\mathrm{N}} 2$ reaction enabling the installation of a ${ }^{18} \mathrm{~F}$ for PET imaging. F-CRANAD 101 showed high affinity for $A \beta$ species, especially for $A \beta$ monomers. Although the fluorogenic properties of F-CRANAD-101 was relatively limited, it was used in mono- and two-photon ex vivo microscopy to image $A \beta$ plaques and cerebral amyloid angiopathy. Thanks to a smart design, [18]F-CRANAD-101 was obtained in a fast and efficient manner thus enabling its use as efficient PET tracer in mice.

Very recently, Yang et al. published in collaboration with Ran a new fluorogenic probe for $A \beta$ oligomers. Based on structural analysis that showed that $A \beta$ oligomers had a triangular protein cavity, they developed PTO-29 (Figure 5B), a V-shaped extended hemicurcuminoid displaying a substituted dioxaborine core. The probe displayed a high affinity towards $A \beta$ oligomers and a good blood brain barrier penetration. Combined to its ability to emit in the NIR region PTO-29 constitutes a suitable $A \beta$ probe for in vivo imaging experiments. $^{62}$

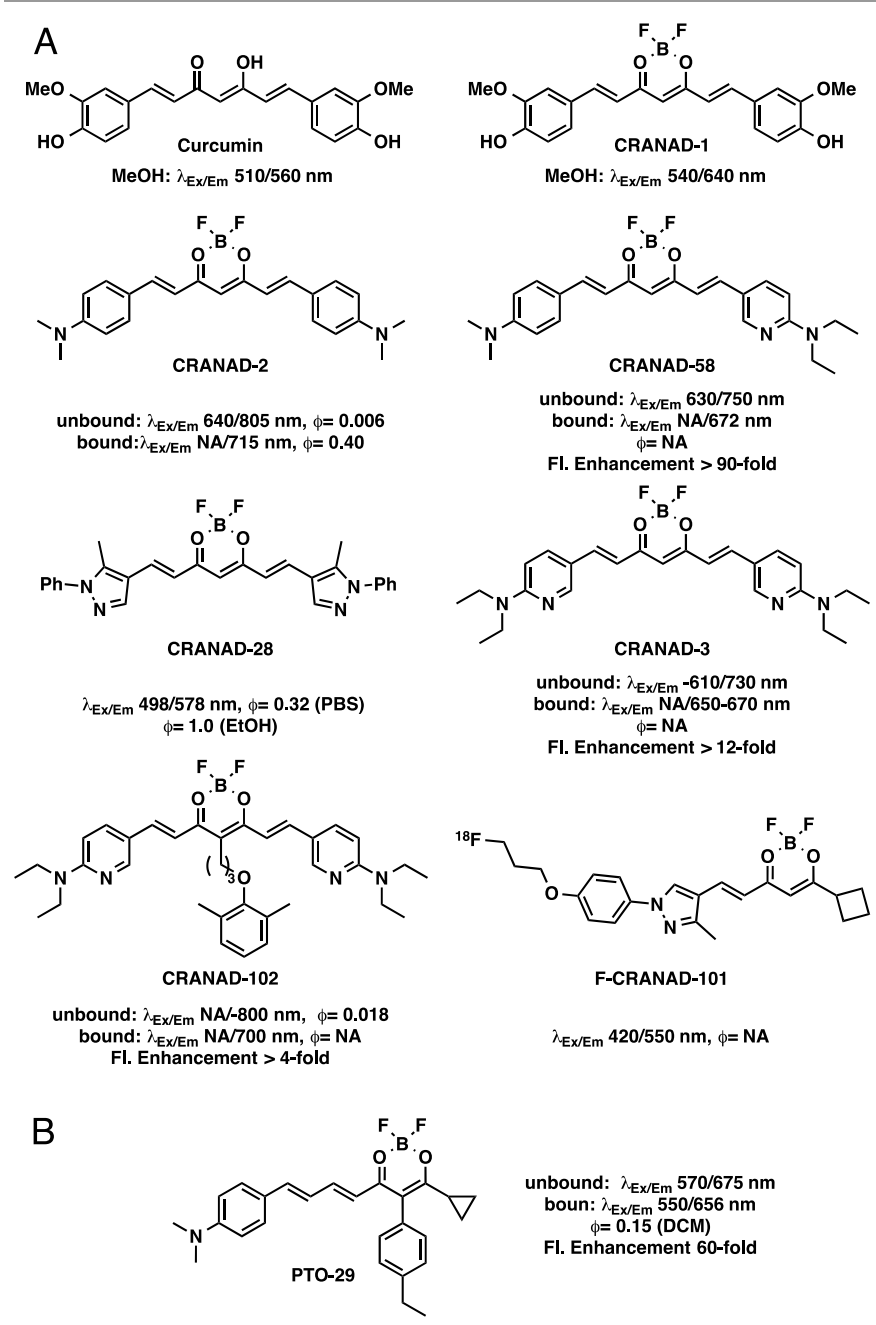

Figure 5. Structures and properties of DBFM probes for $A \beta$ species, from the CRANAD family (A) and other (B).

\subsection{Probes for tau aggregates}

In parallel to $A \beta$ species, hyperphosphorylated tau proteins are also considered as pathological causes of Alzheimer's disease. Based on the work of Moore and Ran, Park et al. synthesized a series of fluorescent regular and extended hemi-curcuminoids and select $\mathbf{2 e}$ as an efficient tau-specific NIR probe (Figure 6). ${ }^{63}$ 2e was shown to be highly specific to tau fibrils compared to $A \beta$ and BSA. The authors reported a 310-fold fluorescence enhancement at $660 \mathrm{~nm}$ upon binding to tau aggregates mentioning a molecular rotor effect. Overall, this probe demonstrated a high potential as a tau-specific fluorogenic 
probe in in vitro and ex vivo bioimaging using human AD brain tissue sections.

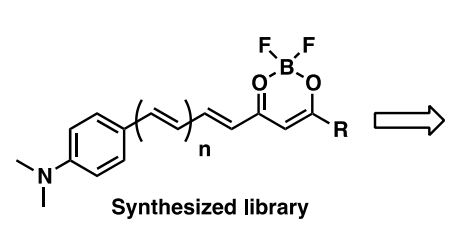

Figure 6. DBFM as probe for tau aggregates.
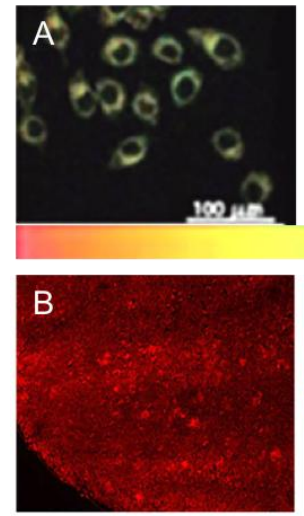

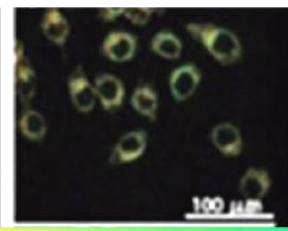

oxygen

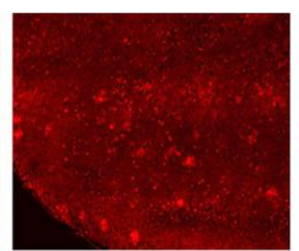

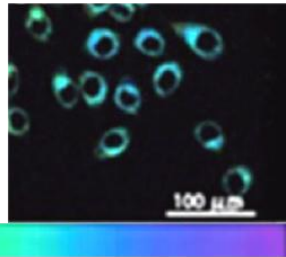

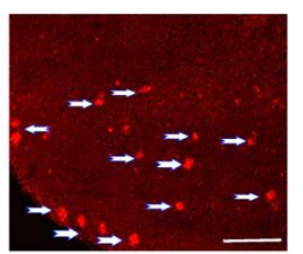

Figure 7. Representative examples of bioimaging performed with DBFM probes for small molecules. (A) Ratiometric imaging using confocal microscopy of HeLa cells loaded with 6, before irradiation (left) and after irradiation in anaerobic conditions (middle) and aerobic conditions (right). Ref. 64, adapted by permission of The Royal Society of Chemistry. (B) Brain slice imaging before addition of CRANAD-88 (left), treated with CRANAD-88 (middle), and treated with CRANAD-88 and $\mathrm{H}_{2} \mathrm{O}_{2}$. White arrows indicate $A \beta$ Plaques. Adapted with permission from ref 68. Copyright (2016), Springer Nature.

Despite the high potential DBFM, only few examples of probes able to detect small molecules playing a relevant role in biological processes have been reported to date. However, two systems can herein be distinguished: ratiometric and fluorogenic probes that upon detection of the target respectively, change their emission wavelengths or display a fluorescence enhancement at a defined emission wavelength. In 2019 Wang et al. reported a ratiometric probe to sense dioxygen. ${ }^{64}$ The authors rationally designed and synthesized various symmetrical and non-symmetrical probes based on dioxaborine and bearing a reactive electron-rich olefin. In the presence of $\mathrm{O}_{2}$ and upon photo-irradiation, singlet oxygen $\left({ }^{1} \mathrm{O}_{2}\right)$ is generated and reacts with the electron-rich olefin of the probe to first form a dioxetane intermediate that finally leads to an indanone derivative. Based on their observation and results, the authors synthesized a PEGylated derivative 6 (Figure 8A) with enhanced water solubility thus suitable for cellular experiments. 6 emits in the yellow region $(560 \mathrm{~nm}$ ) whereas its indanone derivative 6-P arisen from reaction with oxygen is significantly blue shifted $(430 \mathrm{~nm})$. Thanks to this dual emissive system with emissive olefin and ketone forms (in toluene $\phi=0.26$ and 0.88 respectively) ratiometric live cell imaging was performed to quantify intracellular dioxygen concentration in HeLa cells (Figure 7A).

Zhang et al. also reported a ratiometric system using a $\mathrm{BF}_{2^{-}}$ curcuminoid to selectively probe cysteine in mitochondria. ${ }^{65}$ The biphenol curcuminoid was mono propargylated in order to further click a triphneylphosphonium moiety that targets mitochondria in cells and the remaining phenol was esterified as an acrylic ester to obtain DFB1 (Figure 8A). The acrylic moiety undergoes a Michael addition of the cysteine's thiol group then favoring an intramolecular cyclization leading to the uncaging of the probe into DFB-OH. The latter displayed red-shifted absorption and emission spectra $(590 \mathrm{~nm}$ and 680 $\mathrm{nm}$ respectively) compared to DFB1 $(470 \mathrm{~nm}$ and $560 \mathrm{~nm}$ respectively). This feature combined to a high selectivity for cysteine over other biothiols allowed the monitoring of mitochondrial cysteine activity in HeLa cells using dual channel ratiometric imaging.

The design of DFB1 recently inspired Chen et al. who developed CBFA, a cysteine probe based on a symmetrical $\mathrm{BF}_{2-}$ curcumin capped with two acrylic esters (Figure 8B). ${ }^{66}$ Unlike DFB1, CBFA is not ratiometric but instead acts as a fluorogenic probe in the presence of cysteine (11-fold at $615 \mathrm{~nm}$ from CBFA to CBF). Although CBFA does not possess any targeting moiety, it efficiently probes cysteine and glutathione in the cytoplasm of MCF-7 cells.

Previously the same group used a similar approach with a caged $\mathrm{BF}_{2}$-curcumin complex to develop a red fluorogenic probe for biothiols. ${ }^{67}$ After complexation of curcumin with $\mathrm{BF}_{3} \cdot \mathrm{OEt}_{2}$, the two free hydroxyls were caped with 2,4dinitrobenzenesulfonyl (DNBS) groups to obtain CBFB (Figure $8 \mathrm{~B})$. The DNBS groups quenched the fluorescence through photoinduced electron transfer (PET) and are eliminated in the presence of biothiols by a nucleophilic aromatic substitution reaction giving rise to $\mathbf{M - 1}$ (Figure $8 \mathrm{~B}$ ), a red emitting dye (610 $\mathrm{nm}$ ). Interestingly, this study also suggested that the symmetrical di-caged curcuminoid was a more efficient probe than the mono-caged one. The high sensitivity (detection limit $0.59 \mu \mathrm{M})$ of CBFB combined to its important fluorescence enhancement in the presence of cysteine (17.8-fold) allowed to map endogenous biothiols in living HeLa cells.

Taking advantage of their strong experience in curcuminoidbased $A \beta$ probes (See section 2.3), Moore and Ran developed in 2016 an $A \beta$ species-targeted reactive oxygen species (ROS) probe by introducing an hydrogen peroxide reactive moiety to their $A \beta$ probe CRANAD-58. ${ }^{68}$ The modification led to a caged probe named CRANAD-88 (Figure 8B), which is not excitable at $630 \mathrm{~nm}$ and thus "invisible" in the NIR due to the in vivo imaging setup. In the presence of $\mathrm{H}_{2} \mathrm{O}_{2}$, the boronate moiety undergo an oxidation leading to the cleavage of the carbamate link that provokes a red shift of the excitation spectrum thus restoring the NIR emission of the probe $(730 \mathrm{~nm})$ with a fluorescence enhancement of 3-fold. Additionally, in the presence of $A \beta$ aggregates the signal further increased (2.5fold) along with a slight blue shift $\left(\lambda_{E m}=690 \mathrm{~nm}\right)$. Overall, CRANAD-88 displayed an important sequential NIR signal amplification in the presence of $A \beta$ aggregates and $\mathrm{H}_{2} \mathrm{O}_{2}$ allowing to gather important information on the relationship 
between ROS and $A D$ using in vivo imaging in mice models (Figure 7B).

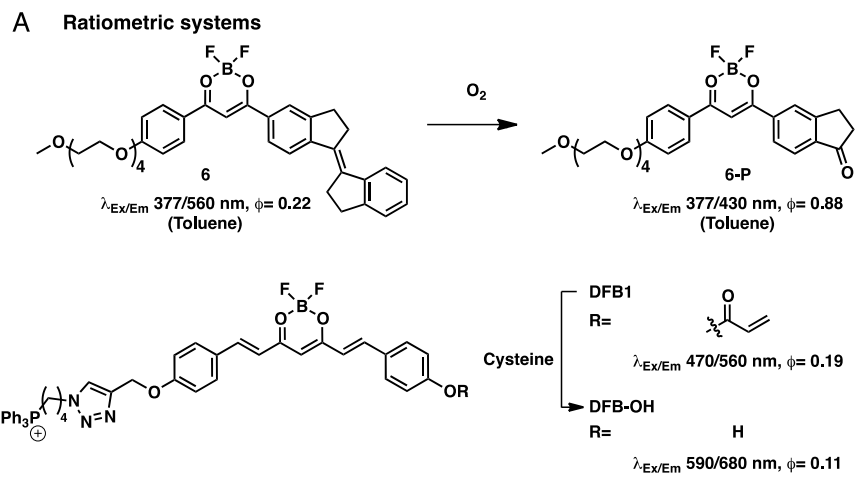

B Fluorogenic systems<smiles>COc1ccc(/C=C/c2c(O)cc(/C=C/c3ccc(O)c(OC)c3)[o+][p+]2F)cc1</smiles>
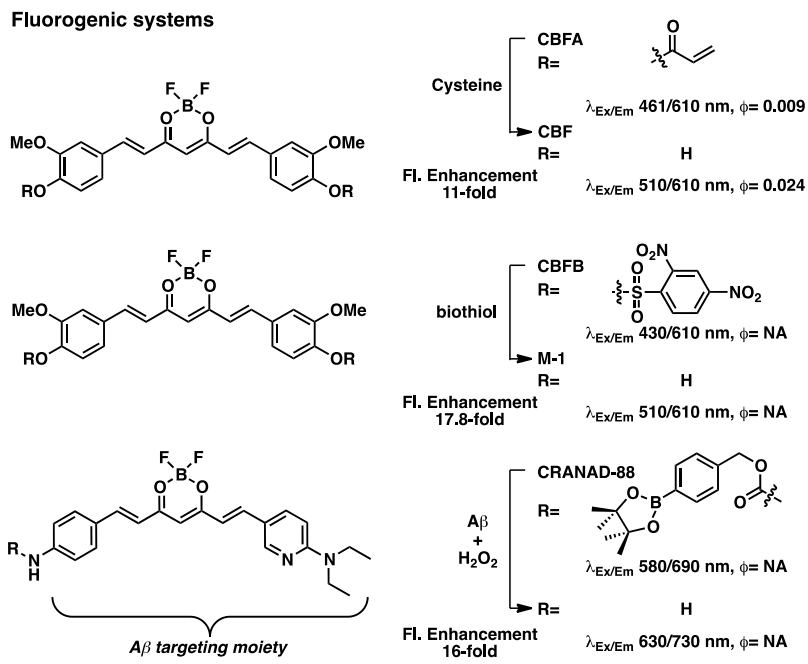

Figure 8. DBFM used as ratiometric (A) and fluorogenic (B) probes for small molecules.

\section{Probes for ions}

Although fluorescent probes for ions have been widely developed, ${ }^{69,} 70,71$ only rare examples incorporates a dioxaborine motif. Once again $\mathrm{BF}_{2}$-curcumin served as a base to develop a fluorogenic probe. Indeed, Li et al. esterified one of the phenol group of $\mathrm{BF}_{2}$-curcumin with a picolinate as a chelating moiety to develop the copper(II) probe 1-Cu (Figure 9). ${ }^{72}$ Upon binding to $\mathrm{Cu}^{2+}$, the probe undergoes a hydrolysis leading back to $\mathbf{B F}_{2}$-Curcumin as the emissive specie provoking a 18-fold fluorescence enhancement in the far-red region $(620$ $\mathrm{nm}$ ). The probe was shown to have a high selectivity towards copper over various cations with a limit of detection $0.12 \mu \mathrm{M}$ and was used in confocal microscopy with B16-F10 cells.

In an older example, Xin et al. used a diphenyl dioxaborine scaffold where a phenolic end was decorated by a methoxy ethylene glycol moiety while at the other end the aniline moiety was acylated with a dipicolyl chelating group (Figure 9). ${ }^{73}$ Upon chelation of $\mathrm{Cd}^{2+}$ the probe 1-Cd undergoes PET quenching thus provoking a 5 -fold fluorescence enhancement in the blue $(463 \mathrm{~nm})$ with no effect on the absorption spectrum. 1-Cd showed good selectivity for $\mathrm{Cd}^{2+}$ over $\mathrm{Zn}^{2+}$ with a dissociation constant of $56 \mu \mathrm{M}$ and served to detect excess of $\mathrm{Cd}^{2+}$ in the cytosol of HeLa cells.

Recently, Jiang et al. developed an anion probe based on dioxaborine. In an uncommon manner the authors used a nopinone scaffold to build their probe called DFT (Figure 9). ${ }^{74}$ The latter possesses a conjugated aldehyde function, which was shown to selectively react with bisulfite $\left(\mathrm{HSO}_{3}{ }^{-}\right)$anions. Upon reaction the probe undergoes a significant bathochromic shift in both absorption and emission from the green emissive DFT to the blue emissive DFT-HSO ${ }_{3}^{-}$. Despite relatively good quantum yields and extinction coefficient of $17,000 \mathrm{M}^{-1} . \mathrm{cm}^{-1}$ and although the authors managed to prove the efficiency of the probe in HeLa cells, both unreacted and reacted forms displayed excitation spectra in the UV region, thus limiting the use of this probe in bioimaging.

Overall, limited examples are given in the literature where DBF were used to develop ion probes. This might be ascribed to the relatively high degree of hydrophobicity that generally characterizes these probes associated to the relative low stability of the boron complex in aqueous media.

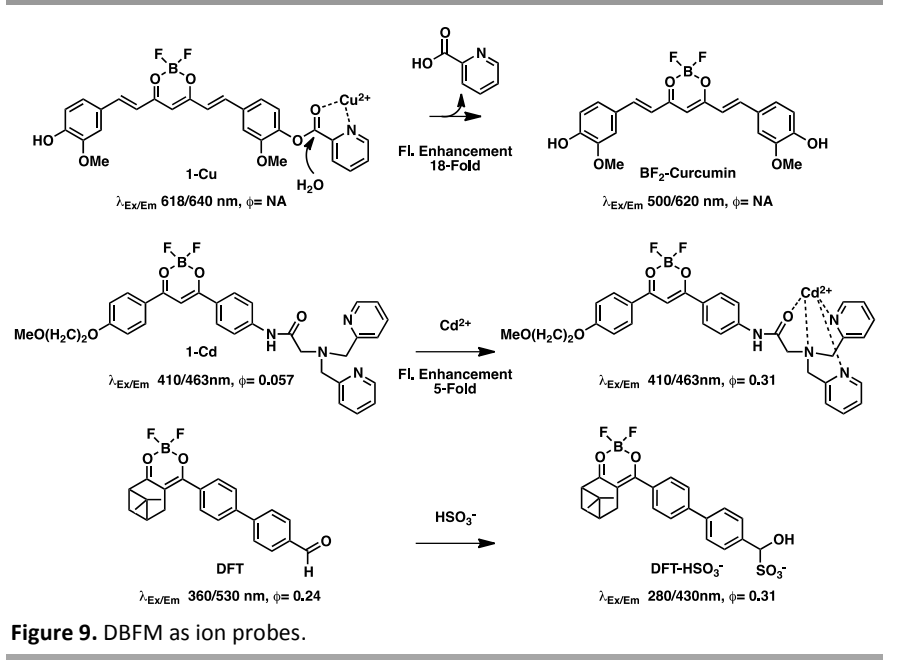

\section{Environment sensitive probes}

Environment sensitive probes including solvatochromic and fluorogenic ones demonstrated their usefulness in bioimaging. ${ }^{75}$ Due to their lipophilic nature DBFM generally display enhanced fluorescence properties in viscous and nonpolar environments such as biomembranes and lipid droplets (LDs) thus making them promising environment sensitive probes. Moreover some of them showed interesting solvatochromic properties allowing to distinguish different lipid compartments in bioimaging. In this section the nonspecific probes possessing interesting solvatochromic properties are first presented, followed by the probes that target specific organelles or receptors. 


\section{ARTICLE}
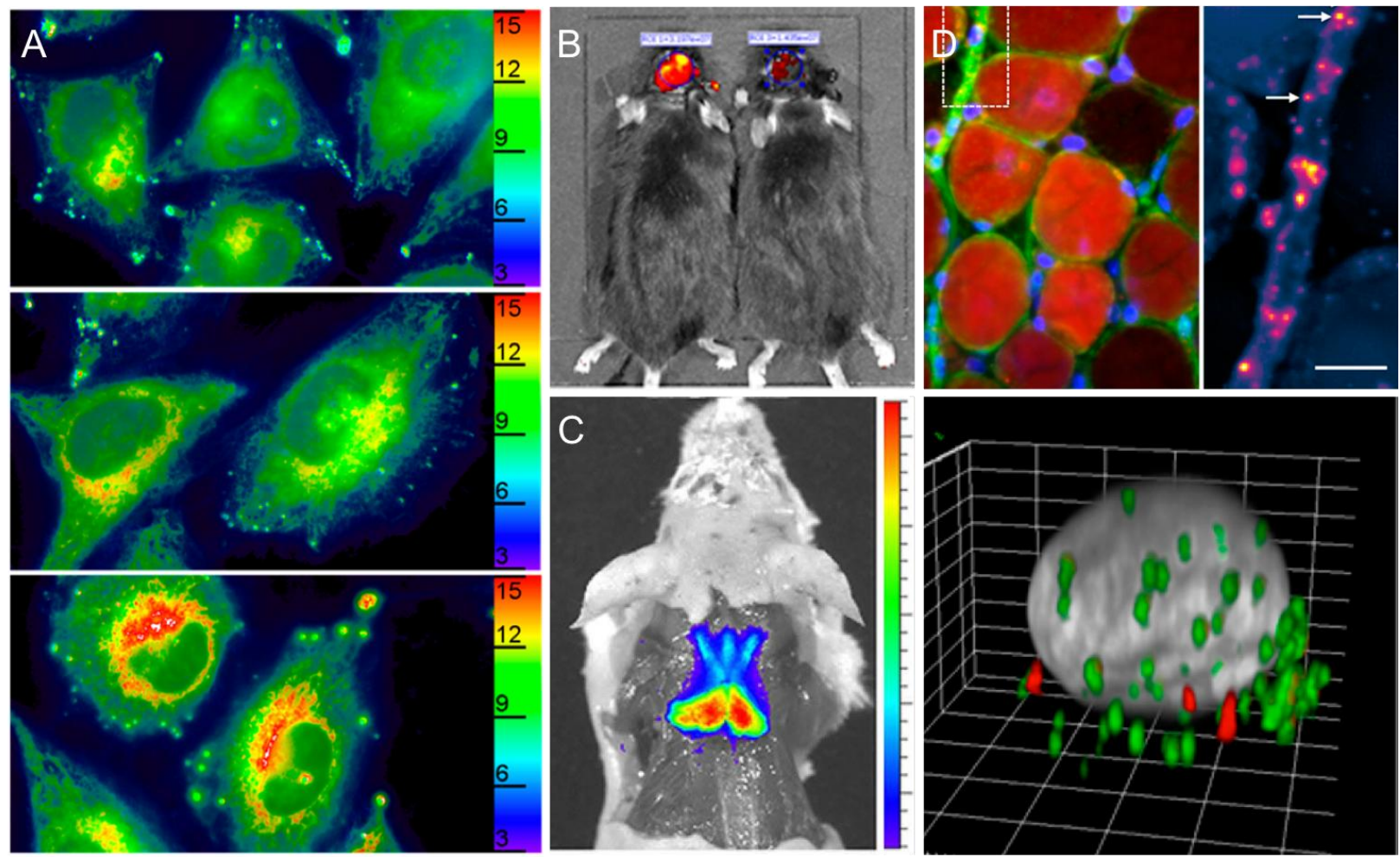

Figure 10. Representative examples of bioimaging performed with DBFM probes for environment. (A) Ratiometric imaging of HeLa cells incubated with DXB-NIR mapping the polarity of intracellular membranes. Top panel is control cells, middle and bottom panels are respectively after $3 \mathrm{~h}$ and $24 \mathrm{~h}$ starvation. Adapted with permission from ref 21 . Copyright (2019) American Chemical Society (B) Fluorescent in vivo imaging using Golgi-P on the brains of mice with depression-like behaviors (right) and control (left). Adapted with permission from ref 80. Copyright (2019) American Chemical Society (C) In vivo imaging of brown adipose tissue after injection of CRANAD-29. Adapted with permission from ref 82. Copyright (2015) Springer Nature (D) Left is an image of adipocytes in mouse adipose tissue after incubation with SMCy 3.5 (neutral lipids, red), Hoechst (nucleus, blue) and MemBright-488 (plasma membrane, green). Right is a zoom on a blood vessel showing circulating lipid vesicles. The bottom panel is a 3D view of a KB cell displaying its LDs (SMCy3.5, green) and LDs from another cell (SMCy 5.5, red). Adapted with permission from ref 20. Copyright (2018) American Chemical Society.

\subsection{Solvatochromic probes}

In 2014, Bai et al. performed di-condensations of 2,2-difluoro1,3-dioxaborylpentadione with various aldehydes to obtain a series of difluoroboron curcuminoids complexes. ${ }^{76}$ The photophysical properties of these donor-acceptor-donor systems revealed that electron rich aldehydes led to bathochromic effects with absorption and emission ranging from $424-597 \mathrm{~nm}$ and $484-681 \mathrm{~nm}$ respectively. Additionally to the high brightness of these fluorophores, the authors showed interesting positive solvatochromic properties up to $96 \mathrm{~nm}$ in emission from toluene to $\mathrm{MeOH}$. Live cell imaging using human gastric cancer cells SGC7901 incubated in the presence of probe 1l (Figure 11) displayed high intracellular signal in the green channel thus demonstrating the low polarity of the targeted subcellular membranes (most likely mitochondria due to the presence of triphenylphosphonium moieties).
Recently, Liu et al. developed the naphthyl-phenyl dioxaborine probe N1 (Figure 11) that displayed typical positive solvatochromism with an impressive shift in emission of 143 $\mathrm{nm}$ from toluene $(555 \mathrm{~nm})$ to DMSO $(698 \mathrm{~nm}) .{ }^{27}$ Although N1 possesses very high quantum yields in non-polar solvents (up to 0.99 ) associated to relatively high extinction coefficients (> $53,000 \mathrm{M}^{-1} \cdot \mathrm{cm}^{-1}$ ) the authors limited its use to the staining of the HeLa's cytoplasm in laser scanning confocal microscopy.

Previously, Zhou et al. synthesized structurally close DBFM bearing a styryl aniline moiety. ${ }^{77}$ Compared to N1, the probes displayed less impressive solvatochromism (up to $51 \mathrm{~nm}$ ). Interestingly, the authors prepared both difluoroboron and dicyanoboron derivative and showed that the latter, 3c (Figure 11), displayed red-shifted absorbance and emission spectra along with higher extinction coefficients (up to $107,700 \mathrm{M}^{-}$ ${ }^{1} . \mathrm{cm}^{-1}$ for $3 \mathrm{c}$ and up to $87,800 \mathrm{M}^{-1} . \mathrm{cm}^{-1}$ for the difluoroboron derivative) combined to higher photostability. Additionally, the 
dicyanoboron complex $3 \mathrm{c}$ was shown to be emissive only in highly non-polar solvents ( $\phi=0.28$ in toluene, $\phi=0.002$ in THF) but also cell-permeable, making it a promising probe for nonpolar environment in cells. Importantly, this study is one of the rare that studied the effect of boron substituents on DBFM and led to valuable data to design new DBFM probes.

In 2018, Rajeshirke et al. introduced DBFM based on a chalcone scaffold bearing a difluoroboron coumarin moiety and a carbazole. ${ }^{18}$ Interestingly the authors studied the difference between the $\mathrm{BF}_{2}$ complex and their non-complexed parent compounds and showed that complexation led to bathochromic effects and enhanced brightness. Among the developed dyes, compound 8 (Figure 11) emits in the far-red region $(600-650 \mathrm{~nm})$ and possesses molecular rotor properties along with a modest solvatochromism of $35 \mathrm{~nm}$ from toluene to $\mathrm{MeOH}$. Although this compound did not lead to bioimaging studies, it inspired Ashoka et al. who replaced the carbazole moiety by an electron rich benzofuryl one to limit the rotor effect and to enhance the push-pull character of the fluorophore. ${ }^{21}$ This modification led to DXB-NIR (Figure 11) that emits in the far-red to NIR with an impressive solvatochromism of $156 \mathrm{~nm}$ from cyclohexane to DMSO. Additionally, DXB-NIR reached high brightness possessing high quantum yields in non-polar solvents (up to 0.93), high extinction coefficients $\left(83,000\right.$ to $\left.128,000 \mathrm{M}^{-1} \cdot \mathrm{cm}^{-1}\right)$ and record two-photon cross section absorption $(13,800 \mathrm{GM}$ at $930 \mathrm{~nm})$. In giant vesicles models, DXB-NIR showed unprecedented difference in emission of $80 \mathrm{~nm}$ when in liquid ordered or in disordered phases. In cell imaging DXB-NIR was found to stain various lipid environments including LDs, endoplasmic reticulum (ER) and at a lower extend the plasma membrane. Splitting the emission signal at $640 \mathrm{~nm}$ into a far-red and a NIR channel led to ratiometric imaging enabling to map the local polarity of these organelles. With this efficient tool in hand, the authors proved that starvation and oxidative stress significantly increased the local polarity of intracellular membranes and LDs (Figure 10A).

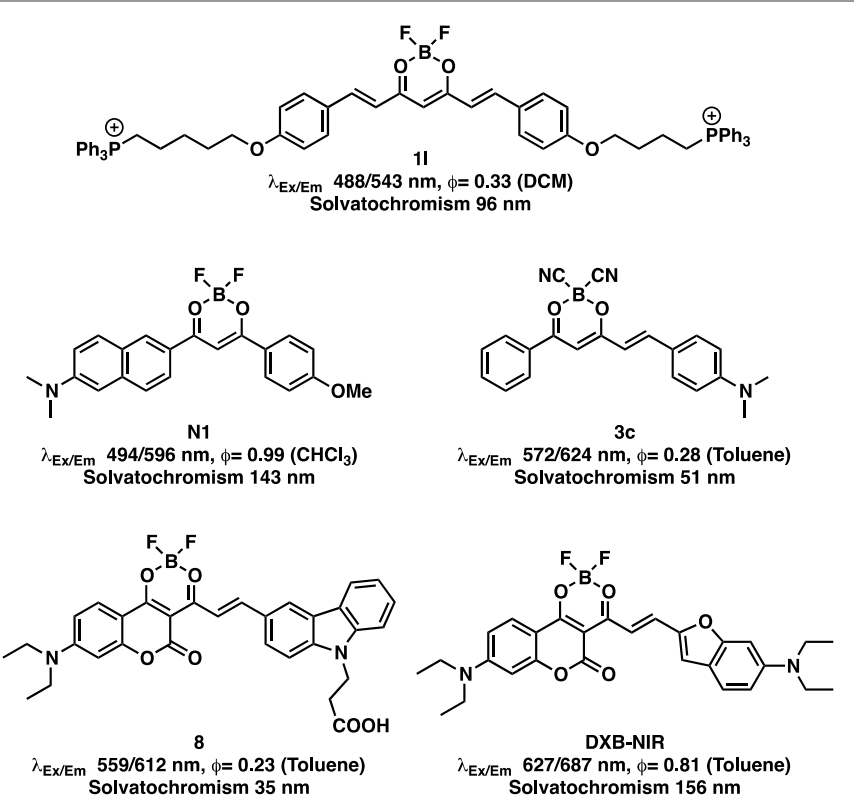

Figure 11. DBFM used as environment sensitive probes.

\subsection{Targeted probes}

Due to their enhanced performances in lipophilic or lipid environments, DFBs were also found suitable to develop targeted probes either by addition of specific targeting moieties or ligands or by rational chemical design.

In 2017, Tang's group developed a targeted DBFM probe using a targeted moiety. They first introduced an original DBFM based on a cyanine 7-chloride scaffold where one end was replaced by a phenyl dioxaborine moiety (Figure 12A). ${ }^{78}$ The obtained merocyanine was coupled to a methyl sulfonamide as an ER-targetable moiety to obtain the targeted polarity sensitive probe ER-P (Figure 12A). ER-P emits in the NIR (786$820 \mathrm{~nm}$ ) and displays positive solvatochromism in both absorbance and emission along with fluorescence enhancement in non-polar solvents. In a first time, the fluorescence properties were used in fluorescence imaging using various cells lines (HL-7702, HeLa, and HePG2). The authors proved the efficient targeting to ER and showed that the fluorescence intensity decreased after stress induction using tunicamycin. In a second time the authors took advantage of the solvatochromic shift in absorbance to perform ratiometric photoacoustic imaging of diabetesinduced liver using two distinct excitation wavelengths at 700 and $800 \mathrm{~nm}$ and showed that the polarity was reversibly increased in liver tissue of diabetic mice. In another work, the same group used ER-P in combination with another fluorescent probe to simultaneously visualize ER polarity and superoxide anion in both cell and in vivo imaging. ${ }^{79}$ In a similar approach, Tang's group slightly modify their polarity sensitive probe by coupling a cysteine in order to obtain Golgi-P (Figure $12 \mathrm{~A})$ that, this time, targets the Golgi apparatus (GA). ${ }^{80}$ After showing that the probe was indeed selective to the GA, the authors showed that the cancer cells (SMMC-7721) presented a lower polarity of the GA compared to non-cancer cells (HL7702). In addition, Golgi-P was used to show that the polarity of GA in non-cancer cells (PC12) was decreased upon oxidative stress induced by excess of glutamate. Taking advantage of the NIR properties of Golgi-P, in vivo imaging were performed to detect the polarity in the living brains of mice (Figure 10B). Very interestingly, the authors observed two-folds decrease in the fluorescence intensity of mice with depression-like behaviors compared to control mice, suggesting that depression is associated to significant enhancement of polarity in the brain.

Targeting of surface receptors has been reported by Karpenko et $a .^{81}$ The authors first developed a red emitting push-pull DBFM called DXB-Red (Figure 12B) displaying high solvatochromism in both absorption and emission (68 and 103 $\mathrm{nm}$ respectively) as well as molecular rotor properties making this probe highly sensitive to its environment. In addition to these appealing properties, DXB-Red displayed high quantum yields (up to 0.93 ), high extinction coefficients (up to 120,000 $\mathrm{M}^{-1} \cdot \mathrm{cm}^{-1}$ ) and enhanced photostability compared to Nile-Red. 
In a second time, DXB-Red was derivatized to a functionnalizable version, which was coupled to carbetocin (CBT), a cyclic peptide that targets the oxytocin G proteincoupled receptor. The obtained DXB-CBT, due to its fluorogenic properties (>1000-fold) in non-polar and viscous environments, was able to specifically probe oxytocin receptors at the surface of HEK293T cells with a concentration as low as $10 \mathrm{nM}$.

Targeting sub-cellular domains or organelles can also be performed by an optimized and rational design of the probe. The first example of optimization in the chemical design to enhance the selectivity of a DBFM was given by Zhang et al. ${ }^{82}$ Following a screening where mice were injected with 38 various NIR emitting dyes, the authors first found that CRANAD-2 and CRANAD-3 (See section 2.3) could stain adipose tissues in vivo in a more selective manner. Moreover, in two-photon cell imaging using 3T3-L1 adipose cells, CRANAD-2 was found to selectively stain the lipid droplets (LDs). The authors then aimed at developing a probe that was selective for brown adipose tissues (BAT) over white adipose tissues (WAT). Similarly to its parent CRANAD analogues, CRANAD-29, a symmetrical difluoroboron curcuminoids complex composed of julolidine as donor moieties (Figure 12B), was synthesized and was shown to stain LDs by facilitated diffusion via transporters (more likely CD36 transporters). Finally, CRANAD-29 displayed excellent selectivity towards BAT over WAT with excellent contrast in in vivo imaging (Figure 10C). These features allowed CRANAD-29 to monitor BAT mass diminution in diabetes-induced mice, BAT activation in cold exposed mice as well as the browning of subcutaneous BAT.

In 2018, we aimed at developing probes selective for LDs and introduced the StatoMerocyanines (SMCys) family. ${ }^{20}$ These probes are composed of a dioxaborine barbituric moiety bearing two cyclohexyl rings that were chosen for their hydrophobicity and bulkiness that avoid affinity with membranes (Figure 12B). Barbituryl-based dioxaborine was first introduced by Zyabrev et al. who proved that this staring material could provide bright anionic fluorophores. ${ }^{83}$ Once linked to indolenine or benzoindolenine moieties through polymethine chains, this barbituryl-based dioxaborine led to 6 different non-charged merocyanines spanning their emission from the yellow $(541 \mathrm{~nm})$ to the NIR $(794 \mathrm{~nm})$. Most of the SMCy displayed very high brightness in oil due to exceptional extinction coefficients (up to $390,000 \mathrm{M}^{-1} \cdot \mathrm{cm}^{-1}$ ) and high quantum yields (up to 1.0). Additionally these probes exhibited among the brightest two-photon absorption (up to 13,200 GM for SMCy5.5). In cell imaging, the SMCy were found to selectively stain the LDs and, thanks to their appealing features, they were successfully used in multicolor cell (KB cells) and tissue (liver, adipose tissue) imaging using various microscopy techniques (Figure 10D). Taking advantage of available probes emitting at different colors, we set up an experiment to demonstrate that cells were able to exchange LDs (Figure 10D). Finally, due to the presence of a pentynyl side arm, SMCy can be functionalizable by copper(I)- catalyzed alkyne-azide cycloaddition (CUAAC). As an example SMCy3 was clicked to a triphenylphosphonium moiety and was thus transformed into a mitochondrial probe. ${ }^{83}$

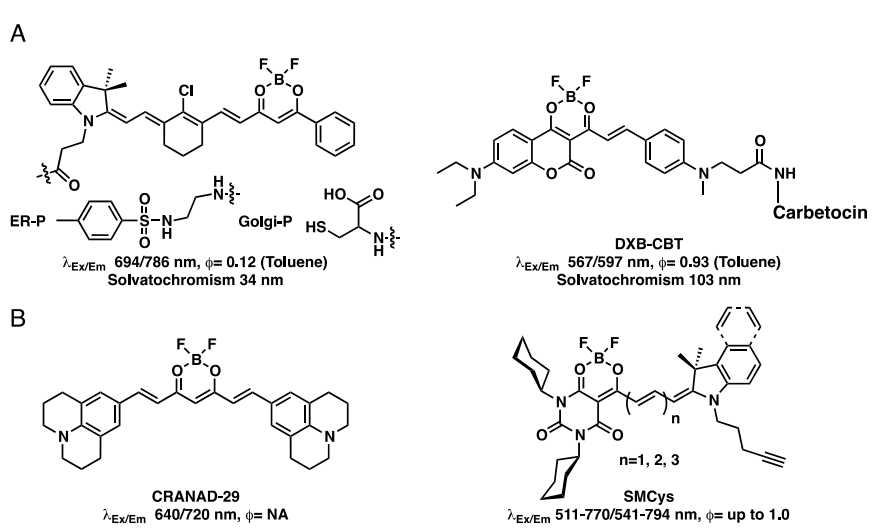

Figure 12. Specific environment sensitive DBFM obtained by $(A)$ addition of specific targeting moieties or ligands and (B) by rational design.

\section{Nanomaterials}

Unlike probes for biomolecules or for ions that must operate in the polar cytoplasmic environments, DBFM when loaded in nanoparticles (NPs) are better adapted and unleash their full potential. Indeed the non-polar core of NPs or their polymeric matrix can prevent form detrimental exposition to aqueous media and thus allow DBFM to display enhanced brightness and stability. During the last decades the group of Fraser significantly contributed in the field of nanostructured DBFM and their applications in responsive materials (see introduction and references). By covalently attaching DBFM fluorophores to various polymer (mainly biocompatible polyesters), Fraser and co-workers developed fluorescent and phosphorescent nanoparticles as well as oxygen sensitive materials.
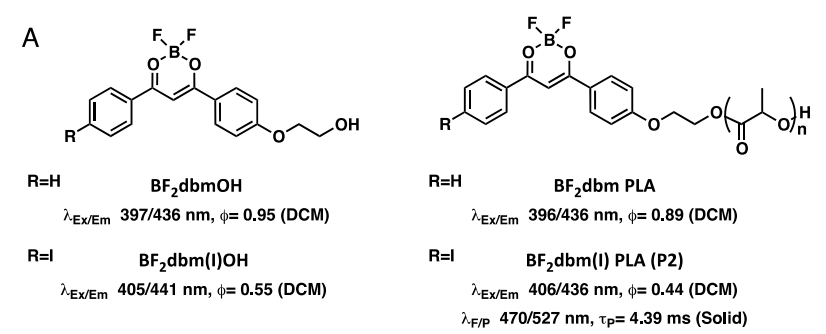

B
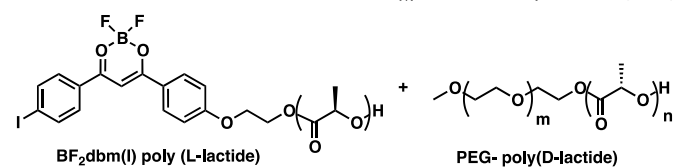

C
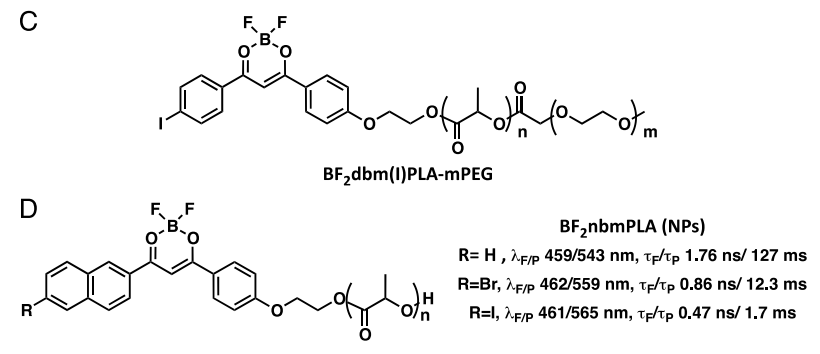
Figure 13. DBFM initiators and polymeric conjugates used as nanomaterials for bioimaging. $\lambda_{F}$ and $\lambda_{P}$ are maximum fluorescence and phosphorescence wavelength respectively. $\tau_{\mathrm{F}}$ 国国目 $\tau_{\mathrm{P}}$ are the mean fluorescence and phosphorescence lifetime respectively.

In 2007, the group used the difluoroboron dibenzoylmethane $\mathbf{B F}_{\mathbf{2}} \mathbf{d b m O H}$ (Figure 13A) as an initiator in the ring opening polymerization of lactide to obtain a fluorescent polylactide $\mathrm{BF}_{2} \mathrm{dbm}$ PLA $\left(\mathrm{Mn}=8,800 \mathrm{~g} \cdot \mathrm{mol}^{-1}\right){ }^{84}$ Both initiator and polymer possess high brightness in DCM (Figure 13A) with extinction coefficient of 53,000 and $36,000 \mathrm{M}^{-1} \cdot \mathrm{cm}^{-1}$ respectively. ${ }^{85}$ Interestingly this new material displayed solid-state fluorescence and exhibited unusual, long-lived green roomtemperature phosphorescence (RTP) and was shown to be responsive to temperature and oxygen. This work paved the way to important publications from this group using polymers loaded with dioxaborine-based fluorophore. In 2010, Contreras et al. used $\mathbf{B F}_{\mathbf{2}} \mathbf{d b m}$ PLA fluorescent NPs of different sizes to study their uptake in HeLa cells. ${ }^{86}$ The authors showed that the NPs were taken up via endocytosis in a lipid-raftdependent manner. Additionally they showed that NPs accumulated within a perinuclear non-lysosomal compartment instead of late endosomes and lysosomes. In addition, $\mathbf{B F}_{\mathbf{2}} \mathbf{d b m O H}$ recently served to develop a library of blue emitting NPs based on biocompatible polymers and block copolymers with PEG that brightly label immune cells in tissue. $^{87}$

Following these pioneer works, Fraser and colleagues used a iodinated derivative to control the oxygen sensitivity and modulate the fluorescence/phosphorescence properties of the material. ${ }^{88} \mathbf{B F}_{\mathbf{2}} \mathbf{d b m}(\mathbf{I}) \mathbf{O H}$ (Figure 13A) served as initiator to synthesize $\mathbf{B F}_{\mathbf{2}} \mathbf{d b m}(\mathbf{I})$ PLA of various size (from 2,700 to 17,600 g. $\mathrm{mol}^{-1}$ ). In the solid state, the fluorescent polymers displayed fluorescence in the blue region $(470 \mathrm{~nm})$ along with a phosphorescence emission in the yellow region (527 nm), the latter being quenched by oxygen (Figure 15A). This feature allowed ratiometric imaging of hypoxia in breast cancer 4T1 mammary carcinoma tumor using both fluorescence and phosphorescent signals in vivo (Figure 15C).

In another work, the group formulated stealth NPs using a stereocomplexation between $\mathbf{B F}_{\mathbf{2}} \mathbf{d b m}(\mathbf{I})$ poly (L-lactide) and PEG- poly(D-lactide) (Figure 13B). ${ }^{89}$ The so-called "boron NPs » (BNPs) were intravenously injected in mice and were shown to be taken up by tumors through enhanced permeability and retention (EPR) effect thus giving potential access to ratiometric imaging of hypoxia in tumors. Indeed, 5 years later the Fraser group prepared dual emissive stealth NPs by incorporating the $\mathbf{B F}_{\mathbf{2}} \mathbf{d b m}(\mathbf{I}) \mathbf{O H}$ in a PLA-PEG block copolymer. $^{90}$ The latter was obtained by coupling $\mathrm{BF}_{2} \mathbf{d b m}(\mathrm{I}) \mathrm{PLA}\left(\mathrm{Mn}=7200 \mathrm{~g} \cdot \mathrm{mol}^{-1}\right)$ to $\mathrm{mPEG}_{2600}-\mathrm{COOH}$ in DCM. The polymer, $\mathbf{B F}_{\mathbf{2}} \mathbf{d b m}(\mathbf{I})$ PLA-mPEG (Figure $13 \mathrm{C}$ ), was nanoprecipitated to provide $94 \mathrm{~nm}$ diameter NPs (PDI=0.23). The authors confirmed that $\mathbf{B F}_{\mathbf{2}} \mathbf{d b m}(\mathbf{I})$ PLA-mPEG NPs kept their dual emissive optical properties as well as their oxygen sensitivity. The NPs were then injected into mice with spontaneous mammary tumors and the ratiometric imaging using fluorescence/phosphorescence signals revealed

differences in oxygen levels within the perivascular regions of the tumor.

Despite the impressive properties of these materials, the photostability of the difluoroboron dibenzoylmethane-based polymer had to be improved. In this endeavor, the group extended the structure to difluoroboron naphthyl-phenyl $(\mathrm{nbm})$ derivatives and studied the effect of additional halide substituents on photophysical properties. $^{91}$ The new fluorophores served as initiators in the polymerization of lactide to obtain 3 different $\mathbf{B F}_{\mathbf{2}} \mathbf{n b m P L A}$ (Figure 13D). Once formulated, the polymers $\left(16,000-20,000 \mathrm{~g} \cdot \mathrm{mol}^{-1}\right)$ gave rise to NPs of 76-82 $\mathrm{nm}$ size with preserved dual emissive properties. $^{92}$ Interestingly, whereas the presence of halide decreased both fluorescence and phosphorescence lifetimes (see Figure 13D), it enhanced the sensitivity to oxygen thus giving access to materials with adjustable ranges of $\mathrm{O}_{2}$ sensitivity. Depending on their fluorescence and phosphorescence properties the different NPs could be used to sense oxygen levels using either phosphorescence lifetime $\left(\tau_{\mathrm{P}}\right)$ imaging (H-NPs and Br-NPs), or fluorescence/phosphorescence ratiometric imaging using a cost-effective RGB camera (Halogenated-NPs). Thanks to their full range sensitivity $\left(0-100 \% \mathrm{O}_{2}\right)$, the iodinated NPs were used to map the oxygen content in wounds of a murine model thus showing a gradual oxygen recovery from hypoxic to normoxic (Figure 15B).

To extend the fluorescence and phosphorescence emission colors of the NPs, four DBFM with different $\pi$-conjugation and donor groups (Figure 14) were coupled to PLA-PEG block copolymers $\left(\sim 11,000\right.$ g. $\left.\mathrm{mol}^{-1}\right)$ using a Mitsunobu reaction or were involved in stereocomplexed NPs. ${ }^{93}$ As expected, the NPs (1NP to 4NP, figure 14), obtained by nanoprecipitation, displayed various colors spanning their fluorescence emission from 420 to $640 \mathrm{~nm}$ (Figure 15D), and possessed different phosphorescence properties. The most red-shifted stereocomplexed NPs (4scNPs) were injected in mice and were shown, using in vivo fluorescence imaging, to accumulate in tumors by EPR effect.

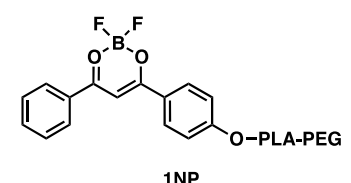

$\lambda_{E x / / F} 380 / 426 / 520 \mathrm{~nm}, \tau_{\mathrm{P}} 104 \mathrm{~ms}$

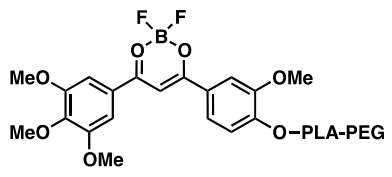

$3 \mathrm{NP}$
$\lambda_{\mathrm{Ex} / \mathrm{F} / \mathrm{P}} 417 / 553 / 556 \mathrm{~nm}, \tau_{\mathrm{P}} 36.6 \mathrm{~ms}$

igure 14. DBFM polymer conjugates with various emission and phosphorescence properties (see figure 15D). 


\section{ARTICLE}
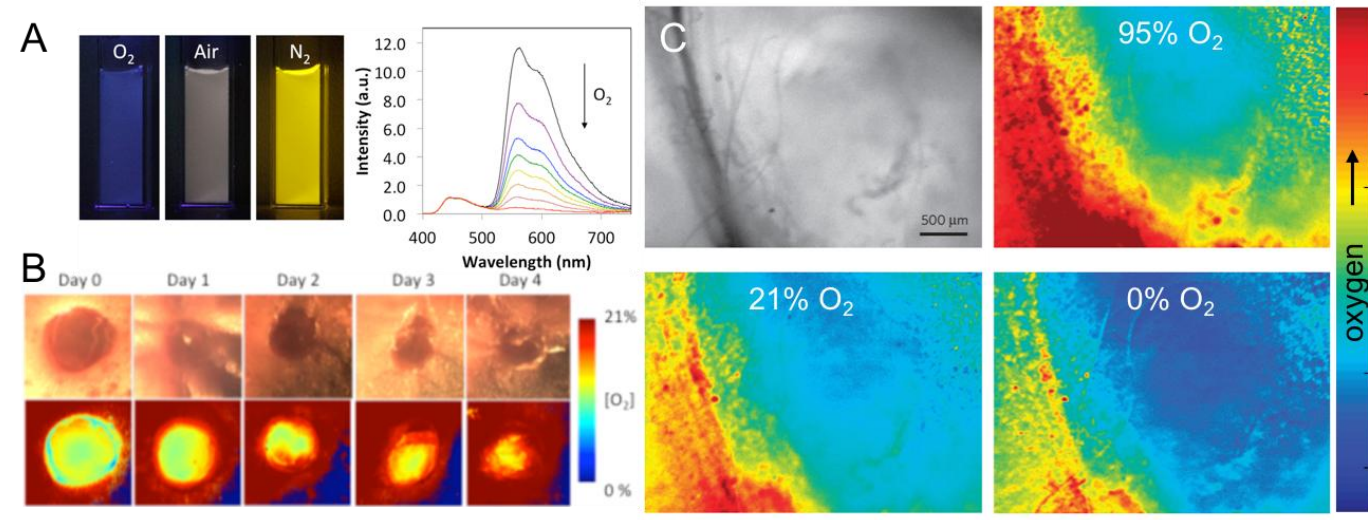

D

PLLA NPS
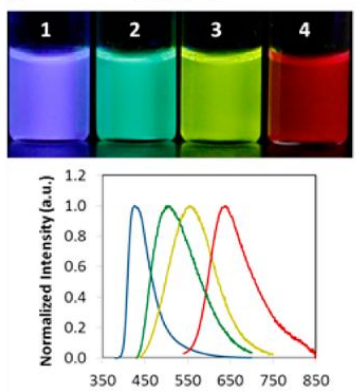

Wavelength $(\mathrm{nm})$
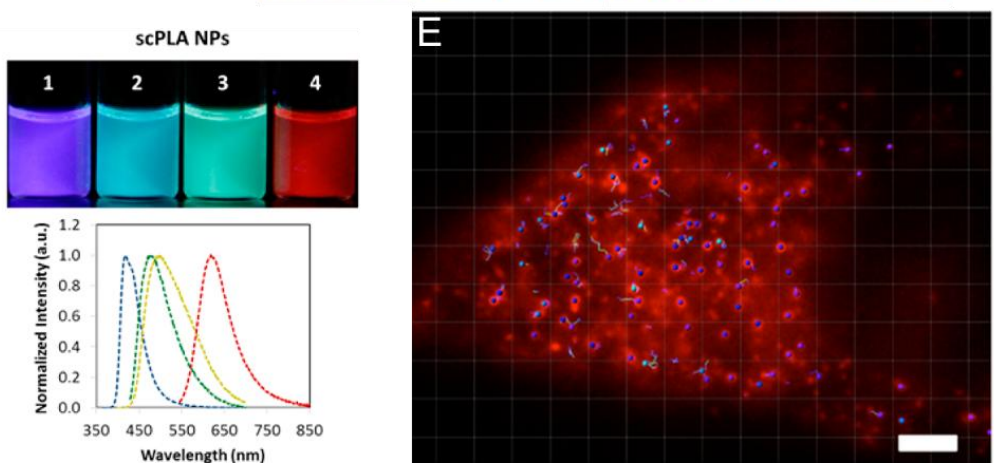

Figure 15. Representative examples of bioimaging performed with DBFM nanomaterials. (A) Example of dioxaborine based fluorescent nanomaterial (BF ${ }_{2}$ nbm(I)PLA NPs) developed by Fraser et al. possessing a fluorescent emission and an oxygen sensitive phosphorescence emission. (B) Application of BF ${ }_{2}$ nbm(I)PLA NPs in ratiometric imaging of wound oxygenation and healing over the time. A and B were adapted with permission from ref 92. Copyright (2016) American Chemical Society (C) In vivo imaging of the breast cancer 4T1 mammary carcinoma tumour using $\mathbf{B F}_{2} \mathbf{d b m}(\mathbf{I})$ PLA NPs and showing tumour hypoxia. Adapted with permission from ref 88 . Copyright (2009) Springer Nature (D) Images and total emission spectra of 1-4 NP (solid lines) and 1-4 stereocomplex NP (dashed lines). Adapted with permission from ref 93. Copyright (2017) American Chemical Society (E)

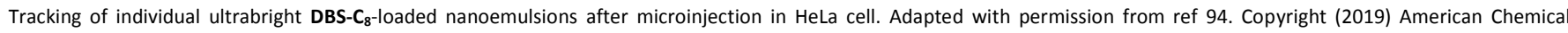
Society.

Unlike these approaches where the fluorophores are covalently incorporated to a polymeric matrix, encapsulation of dioxaborine-based fluorophores in NPs have also been considered. We recently formulated ultrabright NPs by simple encapsulation of new DBFM in nanoemulsions. ${ }^{94}$ Among the biocompatible NPs, nanoemulsions (NEs) benefit from costless and rapid fabrication. They possess an oily core that is stabilized by a surfactant, which confers remarkable stealth properties in biological media. We first developed a new family of DBFM called dioxaborine barbituryl styryl (DBS) composed of a barbituryl dioxaborine moiety connected through a double $\mathrm{C}-\mathrm{C}$ bond to anilines with various substituents. DBS dyes display sharp emission peaks and possess high photostability, high two-photon absorption (up to $730 \mathrm{GM}$ at $980 \mathrm{~nm}$ ) and impressive brightness in oil (with $\varepsilon$ up to $120,000 \mathrm{M}^{-1} \cdot \mathrm{cm}^{-1}$ and $\phi$ up to 0.98). These features allowed us to develop small ( $\sim 40$ $\mathrm{nm}$ ) ultrabright NPs by simple nanoemulsification using vitamin $E$ acetate as the oily core encapsulating a large amount of DBS. Due its hydrophobic nature, we showed that DBS-C $\mathbf{8}_{\mathbf{8}}$ (Figure 16) did not leak out of the oily core in biological media, making it suitable for bioimaging. Finally, thanks to their high individual brightness $\left(30 \times 10^{6} \mathrm{M}^{-1} \cdot \mathrm{cm}^{-1}\right)$ the NEs were individually tracked in HeLa cells after cytosolic microinjection to study their velocity (Figure 15E).

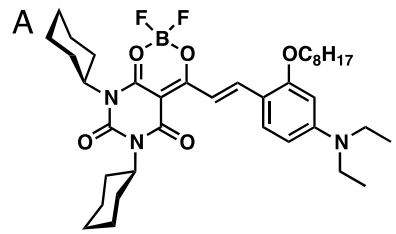

DBS-C 8

$\lambda_{\text {Ex/Em }} 527 / 544 \mathrm{~nm}, \phi=0.86$ (oil) $\lambda^{2}{ }_{\text {Abs }} 980 \mathrm{~nm}, \sigma_{\text {TPA }} 550 \mathrm{GM}$ (Dioxane)

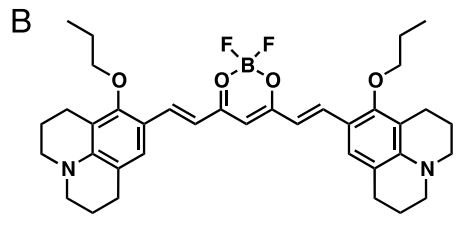

4-BF 2

$\lambda_{\mathrm{EX} / \mathrm{Em}} 616 / 680 \mathrm{~nm}, \phi=0.34$ (EtOAC) $\lambda^{2}{ }_{\text {Abs }} 860 \mathrm{~nm}, \sigma_{\text {TPA }} 515 \mathrm{GM}$ (DCM)
Figure 16. DBFM with two-photon absorption properties, used to load nanoemulsions (A) and porous silica nanoparticles (B). $\lambda^{2}{ }_{\text {Abs }}$ is the maximum two-photon absorption and $\sigma_{\text {月同国 }}$ is the cross section value in two-photon absorption. 
In another example, the group of d'Aléo synthesized a series of $\mathrm{BF}_{2}$-curcuminoid complexes and reported on their solvatochromism property and their high two-photon absorption. Among these new DBFM, 4-BF $\mathbf{H}_{\mathbf{2}}$ possesses electron rich julolidine moieties and displayed a notable NIR brightness in polar environments (Figure 16). In order to preserve the NIR emission once in cells, $\mathbf{4}-\mathbf{B F}_{\mathbf{2}}$ was entrapped in the polar environment of porous silica nanoparticles (PSPNs) that were used as nano-vehicles (size $80-120 \mathrm{~nm}$ ) for bioimaging of BT549 and PANC-1 cells.

\section{Conclusions}

Dioxoborine-based fluorescent materials (DBFM) are readily accessible and proved to possess interesting inherent photophysical properties with potentially high quantum yields, molar extinction coefficients, photostability and multiphotonic absorption. Consequently, promising probes based on dioxaborine rapidly emerged. Although this review showed the wide applications of these materials in bioimaging applications and their efficiency, some limitations remain among which their relatively low chemostability and limited water solubility. ${ }^{50}$ Indeed, whereas DBFM were shown to be particularly efficient in environment preserved from water like in polymer matrix (see Fraser work) or in lipid domains (LDs, ${ }^{20}$ membranes, ${ }^{21,81}$ oil $^{94}$ ), they were proved to be prone to hydrolysis in aqueous media, ${ }^{95}$ thus limiting their use for detection of biomolecules or ions in water-rich cellular environments like in the cytosol. Therefore particular efforts to find more stable dioxaborine motifs must prevail in order to extend the versatility of DBFM. To this aim, using more electron-rich $\beta$-diketonate or introducing bulky substituents might be promising leads. Likewise BODIPY, DBFM with rare exceptions are based on difluoroboron complexes; replacing the fluorine atoms by various groups with different bulkiness or electronic properties might lead to enhanced stability. ${ }^{96}$ Moreover, this approach might help in obtaining water soluble DBFM. ${ }^{97}$ This review also reveals that an important proportion of DBFM is based on curcumin or on the curcuminoid scaffold. Although these motifs are readily accessible and biocompatible, new scaffolds were found to open new horizon towards materials with impressive extinction coefficient, brightness and two-photon absorbance. Those materials, owning to their improved properties, can thus be used at lower concentration in bioimaging thus limiting their potential cytotoxic or phototoxic effects. Moreover, it is highly probable that in the future DBFM will continue to contribute in the development of a new generation of materials with enhanced photophysical properties leading to wide applications where higher brightness is required. The latter includes several domains like 1) in vitro detection using fluorescence spectroscopy of single biomolecules ${ }^{98}$ 2) In cellulo super resolution techniques using single molecules localization microscopy, ${ }^{99,100}$ or stimulated emission depletion (STED) that also require highly photostable materials. ${ }^{101,102}$ 3) Ex vivo deep tissue imaging ${ }^{103}$ 4) In vivo fluorescence imaging using in depth imaging, ${ }^{104}$ or non-invasive whole body imaging ${ }^{105,} 1065$ )
Medical and clinical application, ${ }^{107}$ including diagnosis tools, fluorescent contrast agents and fluorescence guided surgery. In conclusion, this review encourages chemists to develop new DBFM that will certainly lead to a brighter future.

\section{Conflicts of interest}

There are no conflicts to declare

\section{Acknowledgements}

This work was supported by the ANR BrightSwitch 19-CE290005-01. The author would like to thank Dr. Andrey Klymchenko for his suggestions and his group for the support.

\section{Notes and references}

11 J. Chan, S. C. Dodani and C. J. Chang, Nat. Chem., 2012, 4, 973-984.

22 Z. Guo, S. Park, J. Yoon and I. Shin, Chem. Soc. Rev., 2013, 43, 16-29.

33 C. Wu and D. T. Chiu, Angew. Chem. Int. Ed., 2013, 52, 3086-3109.

44 X. He, J. Gao, S. S. Gambhir and Z. Cheng, Trends. Mol. Med, 2010, 16, 574-583.

55 J. Yao, M. Yang and Y. Duan, Chem. Rev., 2014, 114, 6130-6178.

66 L. D. Lavis, Annu. Rev. Biochem., 2017, 86, 825-843.

77 obayashi, H.; Ogawa, M.; Alford, R.; Choyke, P. L.; Urano, Y. Chem. Rev., 2010, 110, 2620-2640.

88 J. R. Lakowicz, Principles of Fluorescence Spectroscopy, Springer Science \& Business Media, 2007.

99 D.-H. Li, C. L. Schreiber and B. D. Smith, Angew. Chem. Int. Ed., 2020, 59, 12154-12161.

1010 N. Boens, V. Leen and W. Dehaen, Chem. Soc. Rev., 2012, 41, 1130-1172.

1111 Y. Kubota, M. Tsukamoto, K. Ohnishi, J. Jin, K. Funabiki and M. Matsui, Org. Chem. Front., 2017, 4, 1522-1527.

1212 B. T. Ferrara and E. P. Thompson, BioTechniques, 2019, 66, 65-71.

1313 K. Kamada, T. Namikawa, S. Senatore, C. Matthews, P.-F. Lenne, O. Maury, C. Andraud, M. Ponce-Vargas, B. Le Guennic, D. Jacquemin, P. Agbo, D. D. An, S. S. Gauny, X. Liu, R. J. Abergel, F. Fages and A. D'Aléo, Chem. Eur. J., 2016, 22, 5219-5232.

1414 D. Venkatakrishnarao, M. A. Mohiddon and R. Chandrasekar, Adv. Opt. Mater., 2017, 5, 1600613.

1515 A. O. Gerasov, M. P. Shandura and Y. P. Kovtun, Dyes Pigments, 2008, 77, 598-607.

1616 A. O. Gerasov, M. P. Shandura and Y. P. Kovtun, Dyes Pigments, 2008, 79, 252-258.

1717 A. O. Gerasov, K. V. Zyabrev, M. P. Shandura and Y. P. Kovtun, Dyes Pigments, 2011, 89, 76-85.

1818 M. Rajeshirke, A. B. Tathe and N. Sekar, J. Mol. Liq., 2018, 264, 358-366.

1919 F. Wang, D. Song, D. A. Dickie and C. L. Fraser, Chem. Asian J., 2019, 14, 1849-1859.

2020 M. Collot, T. K. Fam, P. Ashokkumar, O. Faklaris, T. Galli, L. Danglot and A. S. Klymchenko, J. Am. Chem. Soc., 2018, 140, 5401-5411.

2121 A. H. Ashoka, P. Ashokkumar, Y. P. Kovtun and A. S. Klymchenko, J. Phys. Chem. Lett., 2019, 10, 2414-2421. 
2222 L. Wang, Z. Zhang, X. Cheng, K. Ye, F. Li, Y. Wang and H. Zhang, J. Mater. Chem. C, 2014, 3, 499-505.

2323 D.-H. Kim, A. D'Aléo, X.-K. Chen, A. D. S. Sandanayaka, D. Yao, L. Zhao, T. Komino, E. Zaborova, G. Canard, Y. Tsuchiya, E. Choi, J. W. Wu, F. Fages, J.-L. Brédas, J.-C. Ribierre and C. Adachi, Nat. Photonics, 2018, 12, 98-104.

2424 A. D’Aléo, M. H. Sazzad, D. H. Kim, E. Y. Choi, J. W. Wu, G. Canard, F. Fages, J.-C. Ribierre and C. Adachi, Chem. Commun., 2017, 53, 7003-7006.

2525 H. Ye, D. H. Kim, X. Chen, A. S. D. Sandanayaka, J. U. Kim, E. Zaborova, G. Canard, Y. Tsuchiya, E. Y. Choi, J. W. Wu, F. Fages, J.-L. Bredas, A. D'Aléo, J.-C. Ribierre and C. Adachi, Chem. Mater., 2018, 30, 6702-6710.

2626 P.-Z. Chen, J.-X. Wang, L.-Y. Niu, Y.-Z. Chen and Q.-Z. Yang, J. Mater. Chem. C, 2017, 5, 12538-12546.

2727 N. Liu, P.-Z. Chen, J.-X. Wang, L.-Y. Niu and Q.-Z. Yang, Chin. Chem. Lett., 2019, 30, 1939-1941.

2828 H. Sasabe, K. Sasaki, M. Mamiya, Y. Suwa, T. Watanabe, N. Onuma, K. Nakao, M. Yamaji and J. Kido, Chem. Asian J., 2017, 12, 2299-2303.

2929 E. V. Fedorenko, A. G. Mirochnik, A. V. Gerasimenko, A. Y Beloliptsev and E. B. Merkulov, Dyes Pigments, 2018, 159, 557-572.

3030 M. Liu, L. Zhai, J. Sun, P. Xue, P. Gong, Z. Zhang, J. Sun and R. Lu, Dyes Pigments, 2016, 128, 271-278.

3131 W. A. Morris, T. Liu and C. L. Fraser, J. Mater. Chem. C, 2014, 3, 352-363.

3232 T. Butler, M. Zhuang and C. L. Fraser, J. Phys. Chem. C, 2018, 122, 19090-19099.

3333 C. A. DeRosa, M. L. Daly, C. Kerr and C. L. Fraser, ChemPhotoChem, 2019, 3, 31-36.

3434 T. Liu, G. Zhang, R. E. Evans, C. O. Trindle, Z. Altun, C. A. DeRosa, F. Wang, M. Zhuang and C. L. Fraser, Chem. Eur. J., 2018, 24, 1859-1869.

3535 A. S. Mathew, C. A. DeRosa, J. N. Demas and C. L. Fraser, Anal. Methods, 2016, 8, 3109-3114.

3636 M. L. Daly, C. A. DeRosa, C. Kerr, W. A. Morris and C. L. Fraser, RSC Adv., 2016, 6, 81631-81635.

3737 W. A. Morris, T. Butler, M. Kolpaczynska and C. L. Fraser, Mater. Chem. Front., 2016, 1, 158-166.

3838 N. Zhao, C. Ma, W. Yang, W. Yin, J. Wei and N. Li, Chem. Commun., 2019, 55, 8494-8497.

3939 D. Dang, H. Liu, J. Wang, M. Chen, Y. Liu, H. H.-Y. Sung, I. D. Williams, R. T. K. Kwok, J. W. Y. Lam and B. Z. Tang, Chem. Mater., 2018, 30, 7892-7901.

4040 W. A. Morris, M. Kolpaczynska and C. L. Fraser, J. Phys. Chem. C, 2016, 120, 22539-22548.

4141 A. Kuno, M. Fujiwara, Y. Haketa and H. Maeda, Chem. Asian J., 2019, 14, 1777-1785.

4242 A. Kuno, N. Tohnai, N. Yasuda and H. Maeda, Chem. Eur. J., 2017, 23, 11357-11365.

4343 N. Oka, F. Ito, Y. Haketa, H. Maeda, T. Miyano, N. Tohnai, S. Ito, H. Miyasaka and S. Ozeki, Chem. Eur. J., 2018, 24, 4343-4349.

4444 Y. Terashima, M. Takayama, K. Isozaki and H. Maeda, Chem. Commun., 2013, 49, 2506-2508.

4545 Y. Haketa, D. Katayama, S. Fukunaga, Y. Bando, T. Sakurai, W. Matsuda, S. Seki and H. Maeda, Chem. Asian J., 2016, 11, 2025-2029.

4646 H. Maeda, K. Chigusa, T. Sakurai, K. Ohta, S. Uemura and S. Seki, Chem. Eur. J., 2013, 19, 9224-9233.

4747 J. N. Wilson, J. Wigenius, D. R. G. Pitter, Y. Qiu, M. Abrahamsson and F. Westerlund, J. Phys. Chem. B, 2013, 117, 12000-12006.

4848 D. R. G. Pitter, A. S. Brown, J. D. Baker and J. N. Wilson, Org. Biomol. Chem., 2015, 13, 9477-9484.

4949 Q. Sun, W. Wang, Z. Chen, Y. Yao, W. Zhang, L. Duan and J. Qian, Chem. Commun., 2017, 53, 6432-6435.
5050 A. Gerasov, M. Shandura, Y. Kovtun, M. Losytskyy, V. Negrutska and I. Dubey, Anal. Biochem., 2012, 420, 115-120.

5151 B. Bai, C. Yan, Y. Zhang, Z. Guo and W.-H. Zhu, Chem. Commun., 2018, 54, 12393-12396.

5252 K. Fam, M. Collot and A. S. Klymchenko, Chem. Sci., 2020 $11,8240-8248$

5353 C. Ran, X. Xu, S. B. Raymond, B. J. Ferrara, K. Neal, B. J. Bacskai, Z. Medarova and A. Moore, J. Am. Chem. Soc., 2009, 131, 15257-15261.

5454 E. K. Ryu, Y. S. Choe, K.-H. Lee, Y. Choi and B.-T. Kim, J. Med. Chem., 2006, 49, 6111-6119.

5555 F. Yang, G. P. Lim, A. N. Begum, O. J. Ubeda, M. R Simmons, S. S. Ambegaokar, P. P. Chen, R. Kayed, C. G. Glabe, S. A. Frautschy and G. M. Cole, J. Biol. Chem., 2005, 280, 5892-5901.

5656 X. Zhang, Y. Tian, Z. Li, X. Tian, H. Sun, H. Liu, A. Moore and C. Ran, J. Am. Chem. Soc., 2013, 135, 16397-16409.

5757 X. Zhang, Y. Tian, P. Yuan, Y. Li, M. A. Yaseen, J. Grutzendler, A. Moore and C. Ran, Chem. Commun., 2014, 50, 11550-11553.

5858 K. Ran, J. Yang, A. V. Nair, B. Zhu and C. Ran, Molecules, 2020, 25, 863.

5959 X. Zhang, Y. Tian, C. Zhang, X. Tian, A. W. Ross, R. D. Moir H. Sun, R. E. Tanzi, A. Moore and C. Ran, P. Natl. Acad. Sci. USA, 2015, 112 (31), 9734-9739.

6060 Y. Li, J. Yang, H. Liu, J. Yang, L. Du, H. Feng, Y. Tian, J. Cao and C. Ran, Chem. Sci., 2017, 8, 7710-7717.

6161 J. Yang, R. Cheng, H. Fu, J. Yang, M. Kumar, J. Lu, Y. Xu, S. H. Liang, M. Cui and C. Ran, Chem. Commun., 2019, 55, 3630-3633.

6262 J. Yang, F. Zeng, X. Li, C. Ran, Y. Xu and Y. Li, Chem. Commun., 2020, 56, 583-586.

6363 K. Park, M. K. Kim, Y. Seo, T. Ha, K. Yoo, S. J. Hyeon, Y. J. Hwang, J. Lee, H. Ryu, H. Choo and Y. Chong, ACS Chem. Neurosci., 2017, 8, 2124-2131.

6464 J.-X. Wang, L.-Y. Niu, P.-Z. Chen, Y.-Z. Chen, Q.-Z. Yang and R. Boulatov, Chem. Commun., 2019, 55, 7017-7020.

6565 P. Zhang, Z.-Q. Guo, C.-X. Yan and W.-H. Zhu, Chin. Chem Lett., 2017, 28, 1952-1956.

6666 D. Chen, Z. Long, Y. Dang and L. Chen, Dyes Pigments, 2019, 166, 266-271.

6767 D. Chen, J. Yang, J. Dai, X. Lou, C. Zhong, X. Yu and F. Xia J. Mater. Chem. B, 2018, 6, 5248-5255.

6868 J. Yang, J. Yang, S. H. Liang, Y. Xu, A. Moore and C. Ran, Sci. Rep., 2016, 6, 1-8.

6969 G. R. C. Hamilton, S. K. Sahoo, S. Kamila, N. Singh, N Kaur, B. W. Hyland and J. F. Callan, Chem. Soc. Rev., 2015, 44, 4415-4432.

7070 J. Yin, Y. Hu and J. Yoon, Chem. Soc. Rev., 2015, 44, 46194644 .

7171 S.-H. Park, N. Kwon, J.-H. Lee, J. Yoon and I. Shin, Chem. Soc. Rev., 2020, 49, 143-179.

7272 Y. Li, Y.-X. Ji, L.-J. Song, Y. Zhang, Z.-C. Li, L. Yang and W.C. Huang, Res. Chem. Intermed., 2018, 44, 5169-5180.

7373 L. Xin, Y.-Z. Chen, L.-Y. Niu, L.-Z. Wu, C.-H. Tung, Q.-X. Tong and Q.-Z. Yang, Org. Biomol. Chem., 2013, 11, 30143019.

7474 Q. Jiang, Z. Wang, M. Li, J. Song, Y. Yang, X. Xu, H. Xu and S. Wang, Dyes Pigments, 2019, 171, 107702.

7575 A. S. Klymchenko, Acc. Chem. Res., 2017, 50, 366-375.

7676 G. Bai, C. Yu, C. Cheng, E. Hao, Y. Wei, X. Mu and L. Jiao, Org. Biomol. Chem., 2014, 12, 1618-1626.

7777 Y. Zhou, Y.-Z. Chen, J.-H. Cao, Q.-Z. Yang, L.-Z. Wu, C.-H. Tung and D.-Y. Wu, Dyes Pigments, 2015, 112, 162-169.

7878 H. Xiao, C. Wu, P. Li, W. Gao, W. Zhang, W. Zhang, L. Tong and B. Tang, Chem. Sci., 2017, 8, 7025-7030.

7979 H. Xiao, C. Wu, P. Li and B. Tang, Anal. Chem., 2018, 90 , 6081-6088. 
8080 P. Li, X. Guo, X. Bai, X. Wang, Q. Ding, W. Zhang, W. Zhang and B. Tang, Anal. Chem., 2019, 91, 3382-3388.

8181 I. A. Karpenko, Y. Niko, V. P. Yakubovskyi, A. O. Gerasov, D. Bonnet, Y. P. Kovtun and A. S. Klymchenko, J. Mater. Chem. C, 2016, 4, 3002-3009.

8282 X. Zhang, Y. Tian, H. Zhang, A. Kavishwar, M. Lynes, A.-L. Brownell, H. Sun, Y.-H. Tseng, A. Moore and C. Ran, Sci. Rep., 2015, 5, 1-14.

8383 K. Zyabrev, A. Doroshenko, E. Mikitenko, Y. Slominskii and A. Tolmachev, Eur. J. Org. Chem., 2008, 2008, 15501558.

8484 G. Zhang, J. Chen, S. J. Payne, S. E. Kooi, J. N. Demas and C. L. Fraser, J. Am. Chem. Soc., 2007, 129, 8942-8943.

8585 G. Zhang, J. Chen, S. J. Payne, S. E. Kooi, J. N. Demas and C. L. Fraser, J. Am. Chem. Soc., 2007, 129, 15728-15728.

8686 J. Contreras, J. Xie, Y. J. Chen, H. Pei, G. Zhang, C. L. Fraser and S. F. Hamm-Alvarez, ACS Nano, 2010, 4, 27352747.

8787 M. C. Belanger, M. Zhuang, A. G. Ball, K. H. Richey, C. A. DeRosa, C. L. Fraser and R. R. Pompano, Biomater. Sci., 2020, 8, 1897-1909.

8888 G. Zhang, G. M. Palmer, M. W. Dewhirst and C. L. Fraser, Nat. Mater., 2009, 8, 747-751.

8989 F. R. Kersey, G. Zhang, G. M. Palmer, M. W. Dewhirst and C. L. Fraser, ACS Nano, 2010, 4, 4989-4996.

9090 J. Samonina-Kosicka, D. H. Weitzel, C. L. Hofmann, H. Hendargo, G. Hanna, M. W. Dewhirst, G. M. Palmer and C. L. Fraser, Macromol. Rapid Commun., 2015, 36, 694-699.

9191 D. T. Bowers, M. L. Tanes, A. Das, Y. Lin, N. A. Keane, R. A. Neal, M. E. Ogle, K. L. Brayman, C. L. Fraser and E. A. Botchwey, ACS Nano, 2014, 8, 12080-12091.

9292 C. A. DeRosa, S. A. Seaman, A. S. Mathew, C. M. Gorick, Z. Fan, J. N. Demas, S. M. Peirce and C. L. Fraser, ACS Sens. 2016, 1, 1366-1373.

9393 C. Kerr, C. A. DeRosa, M. L. Daly, H. Zhang, G. M. Palmer and C. L. Fraser, Biomacromolecules, 2017, 18, 551-561.

9494 X. Wang, N. Anton, P. Ashokkumar, H. Anton, T. K. Fam, T. Vandamme, A. S. Klymchenko and M. Collot, ACS Appl. Mater. Interfaces, 2019, 11, 13079-13090.

9595 G. Görlitz and H. Hartmann, Heteroat. Chem., 1997, 8, 147-155.

9696 C. Goze, G. Ulrich and R. Ziessel, J. Org. Chem., 2007, 72, 313-322.

9797 S. L. Niu, G. Ulrich, R. Ziessel, A. Kiss, P.-Y. Renard and A. Romieu, Org. Lett., 2009, 11, 2049-2052.

98 S. Weiss, Science, 1999, 283, 1676-1683.

99 J. B. Grimm, B. P. English, H. Choi, A. K. Muthusamy, B. P. Mehl, P. Dong, T. A. Brown, J. Lippincott-Schwartz, Z. Liu, T. Lionnet and L. D. Lavis, Nat. Methods, 2016, 13, 985-988.

100 H. Li and J. C. Vaughan, Chem. Rev., 2018, 118, 94129454.

101 G. Pacchioni, Nat. Rev. Mater., 2017, 2, 1-1.

102 H. Blom and J. Widengren, Chem. Rev., 2017, 117, 73777427.

103 A. Feuchtinger, A. Walch and M. Dobosz, Histochem. Cell Biol., 2016, 146, 781-806.

104 S. Wang, B. Li and F. Zhang, ACS Cent. Sci., 2020, 6, 13021316.

105 F. Leblond, S. C. Davis, P. A. Valdés and B. W. Pogue, J. Photochem. Photobiol.B, 2010, 98, 77-94.

106 S. K. Piper, C. Habermehl, C. H. Schmitz, W. M. Kuebler, H. Obrig, J. Steinbrink and J. Mehnert, PLOS ONE, DOI:10.1371/journal.pone.0083749.

107 M. Garland, J. J. Yim and M. Bogyo, Cell Chem. Biol., 2016, 23, 122.

108 